\title{
Preparation and Physical Properties of Several Aliphatic Hydrocarbons and Intermediates*
}

\author{
By Frank L. Howard, Thomas W. Mears, A. Fookson, Philip Pomerantz, and \\ Donald B. Brooks
}

\begin{abstract}
In the course of a continuing investigation of the knock ratings of aliphatic hydrocarbons, pure paraffins and olefins have been prepared in quantities sufficient for engine tests. This reports describes the methods of preparation and purification of three pentanes, four hexanes, three heptanes, four octanes, eight nonanes, seven decanes, four hexenes, five octenes, six nonenes, six decenes, and a number of alcohols, ketones, esters, and alkyl halides. Most of these compounds were highly purified. Physical constants measured include freezing point, boiling point, and its variation with pressure, refractive index, and density, and their variations with temperature.**
\end{abstract}

\section{Introduction}

In 1934 the Automotive Section of the National Bureau of Standards undertook an investigation of the impurities in the certified "isooctane" 1 used as a primary standard in the knock rating of fuels. In the course of this work, about a score of paraffin hydrocarbons were isolated, and their physical properties and knock ratings were determined [4]. ${ }^{2}$ The information obtained in this work indicated that some of the higher paraffin hydrocarbons should be decidedly superior to isooctane in knock rating.

The results of this work led in 1936, to a proposal to the National Advisory Committee for Aeronautics that a research project be initiated with the objective of preparing, in quantities sufficient for engine test, the paraffin hydrocarbons likely to be of interest as components of combat aviation fuel. This project was authorized to start July 1, 1937, under joint sponsorship of the National Advisory Committee for Aeronautics, the Army Air Corps (later, Army Air

\footnotetext{
*This paper has been issued by the National Advisory Committee for Aeronautics as Technical Note No. 1247 (1947).

${ }^{* *}$ Several of the compounds investigated, 2,2,3,3-tetramethylpentane, 2,2,3,4-tetramethylpentane, 2,4-dimethyl-3-isopropylpentane, 2 pentamethylpentanes, and 3,3,4,4-tetramethylhexane, are believed to be new ones.

1 The name "isooctane" is a widely accepted trivial name for 2,2,4-trimethylpentane. This nomenclature is used throughout this report.

2 Figures in brackets indicate the literature references at the end of this paper.
}

Forces), and the Navy Bureau of Aeronautics, and has been actively prosecuted since that time.

The results of portions of this investigation completed prior to 1940 have been described in earlier publications $[4,5,6,7]$. The present paper describes the syntheses and physical properties of a number of aliphatic hydrocarbons, some of which have been covered in special restricted reports to the NACA Subcommittee on Aircraft Fuels and Lubricants.

As the objective of this work was the preparation of pure hydrocarbons for engine testing to determine knock rating, it was generally necessary to subordinate other considerations to this purpose. In many cases, it was therefore not possible to make detailed studies of the reactions, or to determine the properties of some of the new or littleknown intermediates.

\section{Apparatus}

\section{Reaction Vessels}

Small-scale exploratory reactions were generally carried out in 5-liter glass flasks. In some cases, where an unusually low yield of final product was expected, 12-liter flasks were used. ${ }^{3}$ For synthesis on a larger scale, two copper reactors were

\footnotetext{
3 The use of 12 -liter flasks was discontinue d in 1944, and reactions of this size were then conducte $d$ in 14-liter brass double-walled vessels similar to the reaction vessels described later.
} 
used initially. Each of these reactors had a capacity of 60 liters and was double-walled. Water at any desired temperature between $5^{\circ}$ and $75^{\circ} \mathrm{C}$ could be circulated in the space between the walls to control the temperature of the reaction. The reactors were equipped with multiple paddle stirrers (60 to $200 \mathrm{rpm}$ ), reflux condensers (multiple copper tube), separatory funnels for addition of reactants, and draw-off valves for removal of products. These reactors were used until early in 1944, when two 50-gallon kettles (one glass-lined, one stainless steel) were put into service. The copper reactors were then used as distillation receivers in conjunction with the large kettles. The large kettles were standard commercial items and were installed so that any temperature between $5^{\circ}$ and $150^{\circ} \mathrm{C}$ could be maintained in the jackets.

\section{Hydrogenation Apparatus}

Hydrogenation reactions were accomplished in high-pressure hydrogenators designed after those described by Adkins [1]. Three sizes were used, with capacities of 1, 3, and 20 liters. The catalyst used was a commercial nickel-on-kieselguhr preparation, which proved to be economical and efficient. No difficulty was encountered in hydrogenating any of the materials, provided they were halogen free. Most of the hydrogenation reactions took place at temperatures below $160^{\circ} \mathrm{C}$, and pressures below $2,000 \mathrm{lb} / \mathrm{in}^{2}$.

\section{Stills}

For convenience, the various stills used in this work are designated in the text by numbers. The salient features of these stills are given in table 1. Some of these columns are no longer in use, having been supplanted by others of later designs. Operations formerly performed in columns 1 and 2 were later carried out in 19 and 20, and columns 8 and 9 were replaced by 17 and 18 . Column 10 was abandoned in 1942 , when column 11 was put into operation. Columns 3 to 7 were replaced by columns 21 to 27 late in 1945.

Still 1.-This still has been previously described [7]. The reflux rate was approximately $1,500 \mathrm{ml} / \mathrm{hr}$ in most cases, the take-off rate being governed by the composition of the charge and the purity desired in the product. Samples of 78 $\mathrm{ml}$ each were removed automatically at predeter-
TaBle 1.-Distillation columns

\begin{tabular}{|c|c|c|c|c|}
\hline Still No. & Type & Size & Packing & $\begin{array}{l}\text { Pot } \\
\text { capacity }\end{array}$ \\
\hline . & & $\mathrm{cm}$ & & $m l$ \\
\hline $1 \ldots$ & $\begin{array}{l}\text { Total reflux in- } \\
\text { term it tent } \\
\text { take-off. }\end{array}$ & 600 by $4.0 \ldots$ & 3/16-in. Pyrex helices & 5,000 \\
\hline $2 \mathrm{a}_{-}$ & & & & 5,000 \\
\hline $3 \ldots$ & $\begin{array}{l}\text { Totalreflux var- } \\
\text { iable take-off. }\end{array}$ & 150 by 2.0 & 3/16-in. glass helices.. & 200 to 5,000 \\
\hline $4 \ldots$ & ..... do ............ & 150 by 2.2 & $\begin{array}{l}\text { 3/32-in. stainless } \\
\text { steel helices from } \\
0.010 \text {-in. wire. }\end{array}$ & 200 to 5,000 \\
\hline $5 \ldots \ldots$ & do & 150 by 2.2 & _... do & 200 to 5,000 \\
\hline $6 \ldots$ & $\ldots$ do $\ldots . .$. & 150 by 2.2 & 3/16-in. glass helices _. & 200 to 5,000 \\
\hline $7 \ldots$ & _. . do do . & 125 by 2.2 & - do & 200 to 5,000 \\
\hline $8 \ldots$ & ........ & 70 by $1.1 \ldots$ & $\begin{array}{l}\text { 1/16-in. N i c hrome } \\
\text { helices from } 0.010- \\
\text { in. wire. }\end{array}$ & 100 to 500 \\
\hline $9 \ldots \ldots$ & $\ldots$ do ..... & 40 by $1.0 \ldots$ & $\begin{array}{l}3 / 64 \text {-in. st a in les s } \\
\text { steel helices from } \\
0.0065 \text {-in. wire. }\end{array}$ & 250 \\
\hline $10 \ldots$ & _. do $\ldots \ldots$ & 243 by 5.1 & Sash chain ............ & 40,000 \\
\hline $11 \ldots \ldots$ & $\ldots$ do $\ldots$ & 600 by $5.1 \ldots$ & $\begin{array}{l}35 \text {-in. } 1 / 2 \text {-in. car- } \\
\text { bon raschig rings, } \\
\text { then } 200 \text { in. } 3 / 32- \\
\text { in. stainless steel } \\
\text { helices from } 0.010- \\
\text { in. wire. }\end{array}$ & 75,000 \\
\hline $12 \& 13 \ldots$ & ..... do ...... & 1,600 by 10.2 & $\begin{array}{l}\text { 3/8-in. porcela in } \\
\text { raschig rings. }\end{array}$ & 227,000 \\
\hline $14 \ldots$ & ..... do .. & 1,600 by 5.1 & $\begin{array}{l}19.7 \text { in. } 3 / 8 \text {-in. porce- } \\
\text { lain raschig rings, } \\
\text { followed by } 600- \\
\text { in. } 3 / 32 \text {-in. stain- } \\
\text { less steel helices } \\
\text { from } 0.010 \text {-in. wire. }\end{array}$ & 227,000 \\
\hline $16 \ldots$ & _... do & 1,600 by 2.7 & _... do do & 113,000 \\
\hline $17 \ldots \ldots$ & $\begin{array}{l}\text { Podbielniak hy- } \\
\text { percal. }\end{array}$ & 127 by $0.8 \ldots$ & Heli-grid ............. & 250 to 5,000 \\
\hline $18 \ldots \ldots$ & _. do do......... & 127 by 2.5 & _. do & 250 to 5,000 \\
\hline $19 \& 20 \ldots$ & _... do do & 250 by $2.5 \ldots$ & _... do do & 250 to 5,000 \\
\hline $21 \ldots$ & $\begin{array}{l}\text { Dephlegmator } \\
\text { controlled } \\
\text { take-off. }\end{array}$ & 120 by $3.5 \ldots$ & 3/16-in. glass helices & 22,000 \\
\hline 22 to 25 & $\begin{array}{l}\text { Total reflux var- } \\
\text { iable take-off. }\end{array}$ & 183 by 2.5 & $\begin{array}{l}\text { 3/32-in. s tainless } \\
\text { steel helices from } \\
0.010 \text {-in. wire. }\end{array}$ & 500 to 5,000 \\
\hline $26 \& 27 \ldots$ & ... do & 183 by $2.5 \ldots$ & 3/16-in. glass helices.. & 500 to 5,000 \\
\hline
\end{tabular}

a See text.

mined intervals of $1 / 2$ to $24 \mathrm{hr}$. The efficiency is approximately 90 to 95 theoretical plates, and the holdup is $260 \mathrm{ml}$.

Still 2.- The column of this still consists of 150 actual plates, following the design by J. H. Bruun [8]. The volume of each fraction removed was $65 \mathrm{ml}$. Reflux rate was about 800 $\mathrm{ml} / \mathrm{hr}$. This still has also been described [7]. The mechanisms of operation and sample removal are the same as for still 1 .

In both stills ( 1 and 2 ) the head temperature was followed during the day by means of a platinum resistance thermometer, and the timing operations were scheduled so that samples were 
removed when this temperature (corrected to 760 $\mathrm{mm} \mathrm{Hg}$ ) became reasonably constant (generally to within a change of less than $0.005 \mathrm{deg} \mathrm{C} / \mathrm{hr}$ ).

Stills 3 to 9.- Small stills patterned after those described by Whitmore and Lux [40] were used to remove ether from reaction mixtures, for purification of intermediates, for preliminary purification of final products, and for fractionation of small charges. These stills are designated as 3 to 9 in table 1.

Still 10.-Prior to the construction of other large-capacity stills, still 10 was used for preliminary fractionation of commercial synthetic crudes. The pot was part of a domestic hot-water tank, the column a length of 2 -in. pipe. The take-off was governed by a $1 / 8$-in. needle valve.

Still 11.-In order to have a higher-capacity, higher-efficiency still than No. 10, still 11 was constructed. The entire still is made of monel metal. The reflux rate is about 4 liters/hr, as measured by gain in temperature of the condenser water. The take-off rate is governed by a commercial $1 / 8$-in. solenoid valve operated by an automatic-timing device. The efficiency of the still is about 65 theoretical plates under operating conditions (3.5 to 4.5 liters/hr reflux). Safety devices include overflow tanks for the salvaging of material distilled through the condenser if the water is accidently cut off, a product-overflow tank for retaining material that may be delivered because of faulty operation of the solenoid valve, and a pot-temperature limit control. All openings to the still are vented to the outside of the building.

Stills 12 to 16.-These columns were constructed for analysis of commercial crudes, purification of large quantities of material, and isolation of hydrocarbons from commercial mixtures. These were put into operation in 1943, and later (1945) column 11 was lengthened by $4 \mathrm{ft}$ and added to the group. The take-off on all these stills is governed by a timer and small solenoid valves. Condensers in the larger columns are of the multiple cold-finger type. The columns are heated by resistance wire controlled by variable transformers. Temperatures are measured by copperconstantan thermocouples.

Safety devices include overflow tanks, automatic pot-temperature limit control, forced ventilation, automatic carbon dioxide fire control (controlled by thermal plugs), and automatic warning if the atmosphere approaches a combustible mixture.
The pots of stills 12 to 16 are made of mild steel. The columns of stills 12 and 13 are made of galvanized pipe; the columns of stills 14 and 15 are made of stainless steel. The condensers are of copper, brass, or monel metal.

Credit is due M. R. Fenske [16], of the Petroleum Refining Laboratory at Pennsylvania State College, for advice on the design and operation of stills 11 to 16 .

\section{Methods and Technic}

\section{Preparation of Grignard Reagents}

The preparation of Grignard reagents in large quantities (up to 330 moles) has been found to be subject to the same limitations as the preparation of small amounts, except that the yields, in general, are slightly larger. The methods used in typical runs of representative members of the aliphatic series are given below, and are not repeated in the discussion of the various syntheses. Decomposition of reaction wmplexes formed by the action of Grignard reagents on various compounds followed the classical methods and need not be repeated.

Methylmagnesium bromide.-To the reactor was added 100 gram atoms $(2.43 \mathrm{~kg})$ of magnesium turnings and enough ether to cover the magnesium. A small amount of methyl bromide was added. If reaction did not start immediately, a little methyl iodide (or previously prepared Grignard reagent) was added. After reaction had been initiated, the stirrer was started, and methyl bromide from a cylinder supported from a steelyard was allowed to flow through a coil of copper tubing surrounded by a dry-ice bath where it condensed and dropped into the reaction mixture. Flow was regulated by a small needle valve. After the reaction was well started, cooling water was admitted to the jacket, and methyl bromide was added as fast as it would react. During the addition of methyl bromide, ether was added in 2-liter portions until the total ether added was 20 liters $(200 \mathrm{ml} / \mathrm{gram}$ atom of magnesium). The amount of methyl bromide added was determined by the loss of weight of the cylinder, and it was found that practically no methyl bromide was lost during the operation. After addition of methyl bromide was complete, the reaction mixture was warmed for 2 to $3 \mathrm{hr}$. If the mixture contained sludge or pieces of unreacted magnesium, 
it was allowed to stand until the sludge had settled, then the clear solution was siphoned off. The sludge was then washed with dry ether, allowed to settle, and the siphoning procedure repeated. If the amount of sludge was small, this latter operation was advantageously carried out in a separatory funnel, where the sludge could be drawn off easily.

The yields varied from 88 to 95 percent, based on magnesium as determined by titration. Similar yields were realized when ethylmagnesium chloride was prepared, but in this case slower addition of halide was necessary in order to avoid the formation of appreciable amounts of sludge.

Isopropylmagnesium chloride-Magnesium turnings (1.5 kg, 63 gram atoms) and 5 liters of ether were placed in the reactor, and reaction was started by the addition of a small amount of isopropyl chloride. After the reaction was initiated, the stirrer was started and 1 liter of isopropyl chloride in 2 liters of ether was added slowly. After this first charge of chloride was complete, 5 liters of ether and the rest of the magnesium $(1.5 \mathrm{~kg}, 63$ gram atoms) were added, and cooling water was circulated through the jacket. Then the rest of the chloride and ether was added in the ratio of 1 liter of chloride to 2.0 to 2.5 liters of ether, until a total of 125 moles of chloride and 37.5 liters of ether had been used. This addition was carried out as fast as possible, still keeping the reflux from the condenser dropwise and not in a steady stream. About 35 hrs were required for a 125-mole run. After removal of the clear solution from the sludge, the yield, calculated from titration data, amounted to 90 to 93 percent of the theoretical quantity.

t-Butylmagnesium chloride.-This preparation was carried out in essentially the same manner described above for the preparation of isopropylmagnesium chloride, except that the addition of chloride was necessarily slower, in order to retard formation of hexamethylethane, isobutylene, and diisobutylene. A 70-mole run required approximately $35 \mathrm{hr}$. The latter half of the chloride added was more dilute than the first half [33], and the rate of addition was slowed up progressively as the reaction neared completion. The jacket of the reactor was not cooled as much in this preparation as with the less highly branched halides. The tendency of $t$-butyl chloride to form sludge is much greater than that of the simpler halides, although many runs were made in which practi- cally no sludge was observed. The yields varied from 80 to 92 percent.

\section{Determination of Physical Properties}

From the plots of refractive indices, boiling points, or freezing points of fractions with respect to volume of distillate, those fractions containing the "best" material were selected and used for the determination of physical constants.

The methods used for the determination of physical constants have been described previously [6]. The freezing-point apparatus was modified in December 1944, so that additional control of the rate of cooling could be obtained. This was done by installing a pumping system on the evacuated chamber surrounding the sample, so that the rate of cooling could be governed by the pressure in the evacuated chamber. This modification of the equipment has been adequately described by Mair [24].

The freezing-point data on 2,2,5,5-tetramethylhexane are considered representative and are illustrated in figure 2. Boiling-point data on samples of four compounds are shown in figure 1 . These figures are presented as typical examples of actual measured physical properties.
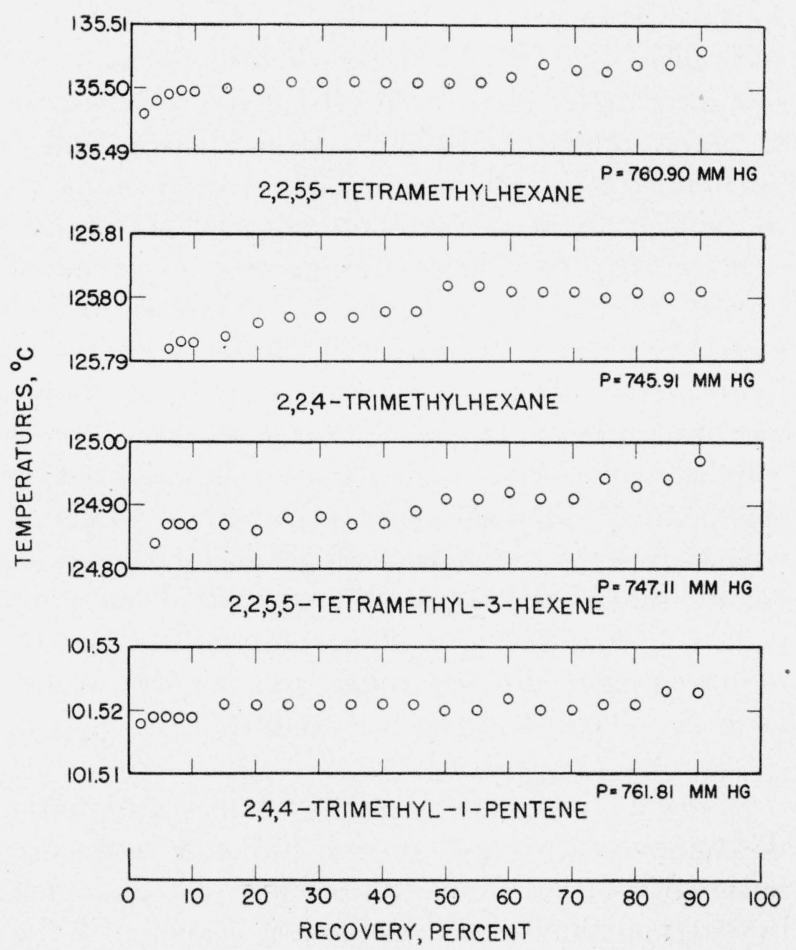

Figure 1.-Distillation curves of four hydrocarbons. 


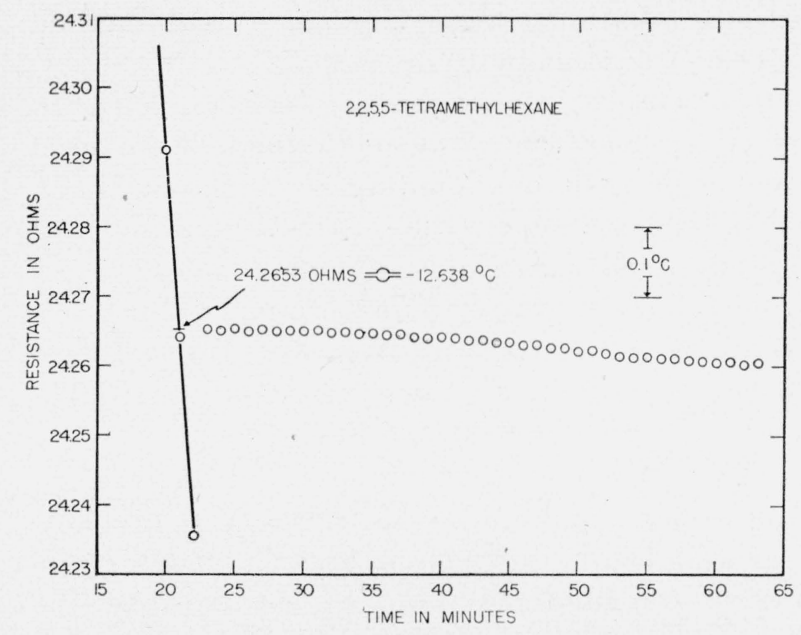

FIGURE 2.-Freezing curve of 2,2,5,5-tetramethylhexane.

Refractive indices were measured on an Abbe type (Valentine) refractometer until 1943, when a Bausch \& Lomb "precision oil" refractometer (also Abbe type) was put into use. Table 6 lists the measured physical properties of the compounds herein.

A rough estimate of the purity of the individual compounds may be made from the " $\Delta T: 20$ to 80 percent" listed beside the boiling-point data in table 6 . This figure is the number of degrees difference between the temperature at which 20 percent of the material had distilled and the temperature at which 80 percent had distilled. The presence of peroxides in the olefin samples tend to make this value extraordinarily large. The ultimate measure of purity is made by a consideration of the freezing point.

\section{Preparation of Materials}

\section{1. n-Pentane}

One gallon of $n$-pentane, which was obtained by purchase, was fractionated in still 1 . From this distillation there was obtained $1,792 \mathrm{ml}$ of material, the fractions of which had a refractive index $\left(n_{D}^{20}\right)$ of 1.3574 to 1.3575 . A "best" sample was selected for determination of physical constants.

\section{2-Methylbutane (Isopentane)}

One gallon of commercial isopentane was fractionated in still 1. There was obtained $2,200 \mathrm{ml}$ of material, $n_{D}^{20}=1.3535$ to 1.3536 , which was collected while the head temperature of the col- umn was $27.87^{\circ}$ to $27.88^{\circ} \mathrm{C}$. Later, a total of 47 liters of high-purity material was prepared from the same source by fractionation in still 11 .

\section{2,2-Dimethylpropane (Neopentane)}

In 1933 Whitmore and Fleming [36] described the preparation of neopentane by reaction between methylmagnesium chloride and $t$-butyl chloride in toluene at $45^{\circ}$ to $50^{\circ} \mathrm{C}$. Yields of 42 to 50 percent were reported. In the present work, a method is described whereby somewhat larger yields of purer product were obtained.

In this work, neopentane was prepared by action of dimethyl zinc on $t$-butyl chloride in toluene at $5^{\circ} \mathrm{C}$. The advantage of causing reaction at this temperature, rather than the often used higher temperature $\left(35^{\circ}\right.$ to $\left.50^{\circ} \mathrm{C}\right)$ for reactions of this type has been previously demonstrated [19]. Dimethyl zinc was prepared in the manner previously reported [19]. However, certain improvements in the technic of handling this material have been made. For these improvements credit is due N. L. Drake and A. Sadle, of the University of Maryland [12].

A 5 liter, single-neck flask, which was used for dimethyl zinc preparation, was placed in an oil bath, and fitted with a $400-\mathrm{mm}$ reflux condenser. To the top of the condenser was attached a bridge of $10-\mathrm{mm}$ glass tubing, which led to the top of a similar reflux condenser attached to a 5-liter, three-neck flask. This latter flask, into which dimethyl zinc was distilled, was situated in a cold-water bath and was provided with a separatory funnel $(500 \mathrm{ml})$ and a stirrer. A side arm on the bridge provided for the introduction of inert gas (carbon dioxide).

The zinc-copper couple from $960 \mathrm{~g}$ of zinc dust and $120 \mathrm{~g}$ of cupric oxide was placed in the oneneck flask, and $1,100 \mathrm{~g}$ (7.75 moles) of methyl iodide added. The temperature of the oil bath was raised to about $45^{\circ} \mathrm{C}$, and a slow stream of carbon dioxide was passed in the side arm of the bridge and out through the separatory funnel, into a venting tube made of $25-\mathrm{mm}$ glass tubing. Reaction between methyl iodide and the couple was complete after $10 \mathrm{hr}$, provided that the couple was sufficiently active. When reaction had ceased, as shown by the cessation of reflux, the carbon dioxide flow was stopped, $500 \mathrm{ml}$ of toluene was added to the three-neck flask, and the top of the separatory funnel was fitted with a 
T-tube. The reflux condenser on the one-neck flask was heated with steam, and the temperature of the oil bath was gradually raised over a period of $2 \mathrm{hr}$ to about $180^{\circ} \mathrm{C}$. This caused the methylzinc iodide in the flask to decompose into dimethyl zinc (and zinc iodide). The dimethyl zinc distilled across the bridge into the toluene in the three-neck flask. Carbon dioxide was allowed to flow through the top of the T-tube while distillation of dimethyl zinc was in progress.

After distillation of dimethyl zinc was complete, the single-neck flask was allowed to cool and the side arm on the bridge connected to a gas-purification train comprising, in the order named, a wash bottle containing water, two bottles containing 85 percent sulfuric acid, an empty bottle, one containing 40 percent potassium hydroxide, a calcium chloride drying tower, and a 100- by 1.5 -cm tube filled with silica gel. After passing through this train, the gas was led into a condensing system comprising a copper-coil condenser at $-10^{\circ} \mathrm{C}$, a receiver at $-78^{\circ} \mathrm{C}$, and finally a trap at $-78^{\circ} \mathrm{C}$.

The flask containing toluene and dimethyl zinc was cooled to $5^{\circ} \mathrm{C}$, and $525 \mathrm{ml}$ (about 4.8 moles) of $t$-butyl chloride in $750 \mathrm{ml}$ of dry toluene was added during $5 \mathrm{hr}$. During the addition of chloride, methane was evolved by the reaction. After the addition of chloride was complete, the reaction mixture was allowed to stand $15 \mathrm{hr}$. Then the bath temperature was raised gradually to $50^{\circ} \mathrm{C}$, during which time more gas was given off, which was not affected by the sulfuric acid and which did not condense in the $-78^{\circ} \mathrm{C}$ trap.

Water was then added to the reaction mixture through the separatory funnel. It was necessary to exercise considerable care in this operation as a violent evolution of neopentane took place at this point. This gas was condensed in the $-10^{\circ} \mathrm{C}$ condenser and solidified in the receiver. There was no discoloration of the sulfuric acid. After about $200 \mathrm{ml}$ of water had been added, and the evolution of gas had subsided, the apparatus was swept out with nitrogen.

The resulting neopentane was transferred to a glass tube and sealed. The yield amounted to $164.5 \mathrm{~g}$, which is 59 percent of that theoretically possible, based on one-half the amount of methyl iodide used. (Two moles of methyl iodide give 1 mole of dimethyl zinc.)

The residue from the distillation of dimethyl zinc, which contained zinc iodide, was used to prepare additional methyl iodide by the method described in Organic Syntheses [28].

In assembling the apparatus, corks coated with shellac, rather than rubber stoppers, were used exclusively. In one preliminary experiment, in which rubber stoppers were used, the product was contaminated with a material that had the odor of methyl mercaptan. Where rubber tubing was necessary in making connections to the side arm on the bridge, arrangement was made so that a minimum of rubber surface was exposed.

The yield reported on the first run was verified later, when nine additional runs of this preparation were made, in which an average yield of 65.6 percent was obtained. In two of these runs, the couple was less active than in the other preparations, and the product was contaminated with methyl iodide. The presence of methyl iodide was characterized by a pink color that developed in the product after a few days. The yield obtained in one run was low because a stoppage developed in the purification train, and some material was lost through a loosened connection.

Freezing-point measurements made on the material from three experiments gave the values $-16.61^{\circ},-16.61^{\circ}$, and $-16.60^{\circ} \mathrm{C}$, respectively. These values may be compared with the value $-16.63^{\circ} \pm 0.10^{\circ} \mathrm{C}$ calculated for the freezing point of 100-percent pure neopentane by Aston and Messerly [2].

\section{3-Methylpentane}

From 75.2 moles of ethylmagnesium chloride and 37 moles of ethyl acetate there was prepared $3,660 \mathrm{ml}$ of 3-methyl-3-pantanol, which was purified by distillation in column 7 (bp $120^{\circ}$ to $124^{\circ} \mathrm{C}$ at $760 \mathrm{~mm}$ ). Dehydration of this carbinol by refluxing with 0.2 percent $\beta$-naphthalene sulfonic acid yielded a mixture of alkenes that boiled at $65^{\circ}$ to $71^{\circ} \mathrm{C}$ at $758 \mathrm{~mm}$. This dehydration would be expected to yield chiefly 3-methyl-2pentene, with a smaller amount of 2-ethyl-1butene. No attempt was made to separate the two olefins as both compounds yield the same alkane when hydrogenated. Hydrogenation of this mixture gave crude alkane, which was filtered through silica gel and distilled in column 4 to yield $1,980 \mathrm{ml}$ of material that boiled at $64.5^{\circ}$ to $65.5^{\circ} \mathrm{C}$ (uncorrected). Redistillation in column 1 gave $1,420 \mathrm{ml}$ of hydrocarbon made up of fractions removed while the head temperature was 
$63.319^{\circ}$ to $63.322^{\circ} \mathrm{C}(761.1 \mathrm{~mm} \mathrm{Hg})$ and for which $n_{D}^{20}=1.3764$ to 1.3765 .

\section{2,2-Dimethylbutane (Neohexane)}

The synthesis of neohexane has been reported previously from this laboratory [7]. Since then, "commercial" neohexane has become available. Several charges of this material were fractionated in stills 1 and 2. From each run, only the latter half of the distillate consisted of material having the properties of neohexane. The forerun contained an impurity of higher refractive index and had a slightly lower boiling point. No extensive investigation was made of this forerun, but the most likely impurity was cyclopentane. This fact was later substantiated by the manufacturer.

A total of 38 liters of purified neohexane was prepared by fractionation of 75 liters of the commercial crude mixture in still 11.

\section{2-Methylpentane}

About 75 liters of commercial crude neohexane was fractionated to prepare 38 liters of 2,2-dimethylbutane. From the distillations of this material there was obtained $3,320 \mathrm{ml}$ of residue, which was fractionated in column 2 into 46 fractions :

\begin{tabular}{l|r|r|r}
\hline \multicolumn{1}{c|}{ Fraction } & $\begin{array}{r}\text { Boiling } \\
\text { range }\left({ }^{\circ} \mathrm{C}\right)\end{array}$ & $\begin{array}{c}\text { Volume } \\
(\mathrm{ml})\end{array}$ & $\begin{array}{r}\text { Refractive } \\
\text { index }\left(n_{D}^{20}\right)\end{array}$ \\
\hline & & & \\
\hline 1 to $22 \ldots 8$ to 60.2 & 1,500 & 1.3748 to 1.3717 \\
23 to $44 \ldots 0.2$ to 60.4 & 1,500 & 1.3715 to 1.3717 \\
45 to $46 \ldots 0.4$ & 140 & 1.3717 to 1.3744 \\
\hline
\end{tabular}

Fractions 35 to 37 were combined, filtered through silica gel, and used in the determinations of physical properties of 2-methylpentane.

\section{Investigation of "Butene Alkylate"}

Seventy-five liters of "butene alkylate" (Humble Oil Co.) was fractionated in still 10. The head temperature was measured by means of a recording thermometer of the gas-expansion type. The reflux ratio was maintained at about 100 to 1 . Fractions of not more than 3.87 liters each were collected, the volume of the fraction depending on the time-temperature curve. After the measurement of refractive indices, like fractions from different runs were combined and refractionated in still 2. Fractionation of the lowest boiling portion from still 10 was carried out first, then the second lowest boiling portion was added to the residue and fractionated, and so on. The refractive index of each fraction was measured, and a plot of refractive index versus fraction number was made. Samples represented by single plateaus were combined and redistilled in column 1 or 2 . Several hydrocarbons were isolated thereby and are listed in table 2 .

\begin{tabular}{|c|c|c|c|c|}
\hline Hydrocarbon & $\begin{array}{c}\text { Boiling } \\
\text { point at } \\
760 \mathrm{~mm} \\
\mathrm{Hg} \\
\text { (Cottrell) }\end{array}$ & $\begin{array}{l}\text { Refractive } \\
\text { index }\left(n_{D}^{20}\right)\end{array}$ & $\begin{array}{l}\text { Volume } \\
\text { isolated }\end{array}$ & $\begin{array}{l}\text { Volume } \\
\text { of total } \\
\text { butene } \\
\text { alkylate }\end{array}$ \\
\hline Isopentane & $\begin{array}{l}{ }^{\circ} \mathrm{C} \\
27.9\end{array}$ & 1.3531 to 1.3533 & ${ }_{728}^{m l}$ & $\begin{array}{r}\text { Percent } \\
0.97\end{array}$ \\
\hline 2, 3-Dimethylbutane... & 57.9 & 1.3749 to 1.3752 & 2,213 & 2. 97 \\
\hline 2-Methylpentane $\ldots . . . .$. & 60.2 & 1.3714 to 1.3716 & 224 & 0.30 \\
\hline 3-Methylpentane & 63.2 & 1.3761 to 1.3763 & 224 & .30 \\
\hline 2, 4-Dimethylpentane.... & 80.5 & 1.3815 to 1.3820 & 2,610 & 3.44 \\
\hline 2, 3-Dimethylpentane & 89.9 & 1.3912 to 1.3920 & 1,034 & 1.37 \\
\hline 2, 2, 4-Trimethylpentane & 99.3 & 1.3912 to 1.3915 & 11,727 & 15.48 \\
\hline
\end{tabular}

a The data in this column represent the amount isolated having the prop. erties shown. It does not constitute an exact analysis of the crude.

\section{(a) 2,3-Dimethylbutane}

The 2,3-dimethylbutane from "butene alkylate", $(2,213 \mathrm{ml})$ was added to $1,255 \mathrm{ml}$ of 2,3-dimethylbutane of approximately the same purity. (This sample of hydrocarbon was furnished by the Standard Oil Co. of Indiana, through the courtesy of D.P. Barnard and R.F.Marschner). The combined material was washed with sulfuric acid, water, sodium carbonate solution, and again with water. After it was dried and filtered through silica gel, it was fractionated in still 2, and gave 2,300 $\mathrm{ml}$ of material, for which $n_{D}^{20}=1.3748$ to 1.3749 .

\section{(b) 2,4-Dimethylpentane}

The 2,4-dimethylpentane from "butene alkylate" $(2,610 \mathrm{ml})$ was refractionated in still 2 . The fractions for which $n_{D}^{20}=1.3816$ to 1.3817 were reserved as the best portion and amounted to $985 \mathrm{ml}$.

\section{2,3-Dimethylpentane From "Isooctane"}

Seventy-five liters of "isooctane" (Phillips Petroleum Co.) was fractionated in still 10 in the manner described in section IV-7. Fractions that distilled between $85^{\circ}$ and $95^{\circ} \mathrm{C}\left(n_{D}^{20}=1.3886\right.$ to 1.3914$)$ were combined $(28,051 \mathrm{ml})$ and refractionated in still 11. From this distillation there was obtained $7,165 \mathrm{ml}$ of hydrocarbon that boiled at $89.7^{\circ}$ to 
$90.0^{\circ} \mathrm{C}\left(n_{D}^{20}=1.3918\right.$ to 1.3921$)$, which was refractionated in still 2. The purified 2,3-dimethylpentane thereby obtained amounted to $4,790 \mathrm{ml}$ after filtration through silica gel. The refractive-index range $\left(n_{D}^{20}\right)$ of various fractions was $1.3919_{1}$ to $1.3919_{6}$.

\section{2,2,3-Trimethylbutane (Triptane)}

The synthesis of triptane involved the following two reactions: (a) The preparation of 2-chloro-2,3dimethylbutane, and (b) the reaction of this chloride with dimethyl zinc.

\section{(a) 2-Chloro-2,3-dimethylbutane}

The apparatus used was similar to that described by Howard [19] for the preparation of 4-chloro2,4,4-trimethylpentane. It was modified so that rubber stoppers were replaced with ground-glass connections. The alkene used was a mixture of 2,3-dimethyl-1-butene and 2,3-dimethyl-2-butene, which was formed by dehydration of pinacolyl alcohol (3,3-dimethyl-2-butanol) [7]. The original alkene mixture contained a small amount of 3,3dimethyl-1-butene in addition to the above-named hexenes, but this hydrocarbon was removed for use in another synthesis.

In $2 \mathrm{hr}, 1,500 \mathrm{ml}$ of the alkene mixture, along with excess hydrogen chloride, was passed through two chambers kept in a bath at $-78^{\circ} \mathrm{C}$. Occasionally it was necessary to remove the baths in order to allow the solidified chloride to melt and pass on through the apparatus. The product was washed with water, with 5 percent sodium bicarbonate solution, again with water, and dried with two successive portions of fresh anhydrous potassium carbonate. Distillation of the resulting material in column 3 gave, after a forerun of unchanged alkene, $675 \mathrm{~g}$ of 2-chloro-2,3-dimethylbutane (bp $69^{\circ}$ to $70^{\circ} \mathrm{C}$ at $190 \mathrm{~mm} \mathrm{Hg}$ ).

\section{(b) Synthesis of Triptane}

In an apparatus like that which was used in the preparation of neopentane (section IV-3), dimethyl zinc was prepared from $1,100 \mathrm{~g}$ (7.75 moles) of methyl iodide and distilled into a 5liter flask containing $500 \mathrm{ml}$ of toluene. The flask was surrounded by ice, and the chloride (600 g, 5 moles) in $1,000 \mathrm{ml}$ of toluene was added during $4 \mathrm{hr}$. The mixture was allowed to stand for $16 \mathrm{hr}$, and was then treated with water and with dilute hydrochloric acid. The reaction product $(2,060 \mathrm{ml})$ was fractionated in column 5 to give a small amount of methyl iodide, some olefinic material presumably consisting of dimethylbutenes formed by dehydrochlorination of alkyl chloride, and $297 \mathrm{ml}$ of crude triptane boiling at $78^{\circ}$ to $83^{\circ} \mathrm{C}$, with $n_{D}^{20}=1.3932$. Two passages through silica gel give a product of the following properties, compared with those of high-purity material:

\begin{tabular}{|c|c|c|}
\hline & $\begin{array}{l}\text { This prepara- } \\
\text { tion }\end{array}$ & $\begin{array}{l}\text { High-purity } \\
\text { material [7] }\end{array}$ \\
\hline Refractive index $\left(n_{D}^{20}\right)$. & 1. 3897 & 1. 38947 \\
\hline Density $\left(d_{4}^{20}\right) \ldots$ & 0.6896 & 0.69000 \\
\hline Freezing point $\left({ }^{\circ} \mathrm{C}\right)$ & -26.1 & -25.059 \\
\hline Boiling point $\left({ }^{\circ} \mathrm{C}\right)$ & $\begin{array}{c}81.0 \\
\text { (Cottrell) }\end{array}$ & 80.879 \\
\hline
\end{tabular}

The yield of crude triptane amounted to 51 percent of the theoretical.

In subsequent experiments it was found that a large excess of alkyl chloride offered no advantage, a 2 to 3 percent excess giving a comparable yield. The excess chloride was found to be easily removed by boiling the crude mixture with a 5percent solution of potassium hydroxide in alcohol.

In each of several experiments, the yield amounted to 46 to 52 percent of crude triptane. The time allowed for addition of chloride was varied from 3 to $8 \mathrm{hr}$ and the temperature of reaction from $0^{\circ}$ to $30^{\circ} \mathrm{C}$ without any appreciable change in yield. In one experiment, in which "isooctane" (2,2,4-trimethylpentane) was used as a solvent, the yield was 48 percent.

Under the conditions of hydrochlorination, 2,3-dimethyl-1-butene was found to add hydrogen chloride more easily than 2,3-dimethyl-2-butene. The unreacted alkene that was recovered when a mixture of the two was hydrochlorinated was found to be practically pure 2,3-dimethyl-2butene.

Very slight decomposition of 2-chloro-2,3dimethylbutane takes place when it is boiled at atmospheric pressure.

\section{2-Methyl-3-ethylpentane}

This octane was prepared by hydrogenation of the olefins which resulted from the dehydration of 2-methyl-3-ethyl-3-pentanol. The carbinol was prepared by the action of ethylmagnesium chloride on isobutyl isobutyrate. 
To a solution containing 90 moles of ethylmagnesium chloride in 20 liters of ether was added $6,335 \mathrm{~g}$ (44 moles) of isobutyl isobutyrate in 10.5 liters of ether. The product was dried with sodium carbonate and distilled in column 6 . There was obtained $5,680 \mathrm{ml}$ of 2-methyl-3-ethyl-3-pentanol $\left(55^{\circ}\right.$ to $57^{\circ} \mathrm{C}$ at $\left.48 \mathrm{~mm} \mathrm{Hg}\right)$. Dehydration was effected by refluxing the carbinol with 0.2 percent by weight of $\beta$-naphthalene sulfonic acid, which gave $5,235 \mathrm{ml}$ of crude alkene mixture, boiling at $114^{\circ}$ to $119^{\circ} \mathrm{C}$. As dehydration of 2-methyl-3ethyl-3-pentanol should yield two alkenes, namely, 2-methyl-3-ethyl-2-pentene (bp ca $117^{\circ} \mathrm{C}$ ) and 4-methyl-3-ethyl-2-pentene (bp ca $116^{\circ} \mathrm{C}$ ), both of which yield the same alkane on hydrogenation, no attempt was made to separate the two. The alkene mixture was dried with calcium chloride and distilled from sodium. A portion of the distillate $(4,721 \mathrm{ml})$ was hydrogenated to the alkane, which, after two distillations from sodium and filtration through silica gel, amounted to $4,050 \mathrm{ml}$. The compound was finally fractionated in still 1 , yielding $3,300 \mathrm{ml}$ of material, which had a refractive index constant within 0.0001 .

\section{2,3,3-Trimethylpentane}

This hydrocarbon resulted from the reaction between isopropylmagnesium chloride and $t$-amyl chloride.

To 90.5 moles of isopropylmagnesium chloride in 30.9 liters of ether solution was added $9,600 \mathrm{~g}$ (90 moles) of $t$-amyl chloride during a period of about $12 \mathrm{hr}$. Stirring was continued until separation of solid material prevented adequate mixing. Then the reaction mixture was allowed to stand 2 to 3 weeks at $15^{\circ}$ to $20^{\circ} \mathrm{C}$ until no more Grignard reagent was present. The product was treated with ice and dilute hydrochloric acid and the resulting organic material distilled in column 3. After a forerun of ether, isoamylene, and $t$-amyl chloride there was obtained $4,400 \mathrm{ml}$ of crude 2,3,3-trimethylpentane ( $31 \%$ yield), which boiled $112^{\circ}$ to $115^{\circ} \mathrm{C}$. When refractionated in column 1 , the crude paraffin gave $3,600 \mathrm{ml}$ of fractions for which $n_{D}^{20}=1.4074$ to 1.4075 . Redistillation of accumulated foreruns from several batches gave an additional quantity of pure material. From several runs a total of 39 liters of pure 2,3,3trimethylpentane was prepared.

Early experiments on this preparation were made in which a large excess of Grignard reagent was assumed to be desirable, but it was found that the yield of product was actually decreased by an excess of Grignard reagent. For example, in one run in which 72 moles of isopropylmagnesium chloride was allowed to react with 57 moles of t-amyl chloride, the yield of 2,3,3-trimethylpentane was only 21 percent. Credit is due Doctors Calingaert, Beatty, and Soroos [9] for the discovery of this improvement in technic, which they made in connection with a similar reaction.

\section{2,2,3-Trimethylpentane and 2,3,4-Trimethylpentane}

There was prepared, by fractionation of several cuts of alkylate mixtures, 38.6 liters of 2,2,3trimethylpentane and 37.9 liters of 2,3,4-trimethylpentane. The source materials were selected fractions of Shell Oil Co. "hot acid octane" (208 liters), Phillips Petroleum Co. "isooctane" (38 liters), Universal Oil Products Co. "isooctane" (45 liters), and previously prepared synthetic material (0.6 liter) [6]. The unresolved alkylates and residues were roughly fractionated in stills 10 and 11 into concentrates rich in 2,2,3-trimethylpentane and 2,3,4-trimethylpentane. These concentrates were redistilled in column 11. Most of the material was obtained by these distillations. Foreruns, intermediates, and afterruns were again fractionated in stills 1 and 2 . From a total of 47 distillations there was obtained $38,610 \mathrm{ml}$ (at $25^{\circ}$ C) of 2,2,3-trimethylpentane $\quad\left(n_{D}^{20}=1.4026\right.$ to 1.4029 ) and $37,955 \mathrm{ml}$ (at $25^{\circ} \mathrm{C}$ ) of $2,3,4$-trimethylpentane $\left(n_{D}^{20}=1.4041\right.$ to 1.4045$)$. Physical constants of the two compounds were measured and agreed well with those measured on the pure materials, as reported previously [6, 7].

\section{2,2,5-Trimethylhexane}

The presence of 2,2,5-trimethylhexane in "isooctane residue" was reported by Brooks, Cleaton, and Carter in 1937 [4]. By distillation of 76 liters of this material ${ }^{4}$ in still 10 , a concentrate rich in this nonane was obtained. This concentrate $\left(4,525 \mathrm{ml}\right.$, bp $123^{\circ}$ to $125^{\circ} \mathrm{C}, n_{D}^{20}=1.399$ to 1.400$)$ was refractionated in still 1 . There was obtained $2,005 \mathrm{ml}$ of 2,2,5-trimethylhexane, with a refractive-index range of 1.3995-1.3996.

4. Supplied by the Rohm \& Haas Co. 


\section{2,3,5-Trimethylhexane}

This nonane was prepared by hydrogenating 2,3,5-trimethyl-2-hexene, which resulted from the reaction of isopropylmagnesium chloride on 1chloro-2,3-dimethyl-2-butene. There was also formed a small amount of 2,3,3,4-tetramethyl-1pentene in this reaction.

\section{(a) 2,3-Dimethyl-1,3-butadiene}

Pinacol hydrate, prepared by the method of Brooks, Howard, and Crafton [7] was dehydrated to anhydrous pinacol by distillation in columns 4 to 7 . These distillations were carried out at atmospheric pressure until the head temperature reached $122^{\circ} \mathrm{C}$, when the pressure was reduced to $80 \mathrm{~mm} \mathrm{Hg}$. At this pressure the anhydrous pinacol distilled at $111^{\circ}$ to $114^{\circ} \mathrm{C}$.

In order to determine the optimum conditions for conversion of the glycol to 2,3-dimethyl-1,3butadiene, a series of test runs were made. The results are shown in table 3 . In these experiments the pinacol was refluxed with the catalyst under columns 5 or 7 . The product of each run was washed, dried, and distilled in column 6 for analysis. From the results of these experiments it was concluded that 48 percent hydrobromic acid was the best catalyst of those tried for this dehydration. By dehydrating several batches of pinacol (2.5 to $3.0 \mathrm{~kg}$ per batch), 17.4 liters of 2,3-dimethyl-1,3-butadiene was prepared, which boiled at $68.5^{\circ}$ to $71.5^{\circ} \mathrm{C}$ at $758 \mathrm{~mm}$.

TABLE 3.-Dehydration of pinacol to 2,3-dimethylbutadiene1,3 and pinacolone (3,3-dimethyl-2-butanone)

\begin{tabular}{|c|c|c|c|c|}
\hline \multirow[b]{2}{*}{ Run } & \multirow[b]{2}{*}{$\begin{array}{l}\text { Pinacol } \\
\text { taken }\end{array}$} & \multirow[b]{2}{*}{ Catalyst } & \multicolumn{2}{|c|}{ Yield of- } \\
\hline & & & $\begin{array}{c}\text { Di- } \\
\text { methyl } \\
\text { butadiene }\end{array}$ & $\begin{array}{l}\text { Pina- } \\
\text { colone }\end{array}$ \\
\hline $1 \ldots$ & ${ }^{g} 453$ & $\begin{array}{l}1.5 \mathrm{~g} \text { of } 48 \text {-percent hydrobromle } \\
\text { acid. }\end{array}$ & $\begin{array}{r}\text { Percent } \\
45\end{array}$ & $\begin{array}{r}\text { Percent } \\
19\end{array}$ \\
\hline $2 \ldots$ & 500 & $\begin{array}{l}5.0 \mathrm{~g} \text { of } \beta \text {-naphthalene sulfonic } \\
\text { acid. }\end{array}$ & 36 & 34 \\
\hline $3 \ldots \ldots$ & 500 & $5.0 \mathrm{~g}$ of $p$-toluene sulfonic acid & 40 & 31 \\
\hline $4 \ldots \ldots$ & 500 & $7.0 \mathrm{~g}$ of aniline hydrobromide.... & 18 & 15 \\
\hline
\end{tabular}

(b) 1-Chloro-2,3-dimethyl-2-butene

The addition of hydrogen chloride to 2,3dimethyl-1,3-butadiene was accomplished in the apparatus described by Howard [19]. The reaction chambers were kept at $-30^{\circ} \mathrm{C}$, and dry hydrogen chloride and alkadiene was added simultaneously. The daily output of the apparatus was 1.0 to 1.5 liters of chloride. The product was freed of dissolved hydrogen chloride by aeration with carbon dioxide and stored over sodium carbonate. Distillation analysis showed that the reaction was practically quantitative. The product used for further synthesis boiled at $32^{\circ} \mathrm{C}$ at $45 \mathrm{~mm} \mathrm{Hg}$.

\section{(c) 2,3,5-Trimethyl-2-hexane}

To an ether solution of 62 moles of isopropylmagnesium chloride was added $7.32 \mathrm{~kg}$ of 1-chloro2,3-dimethyl-2-butene. The reaction mixture became very viscous, and it was necessary to add more ether at intervals. The reaction was worked up after 4 days, and the organic material was dried, the ether removed, and the crude residue distilled through column 3 (bp $70^{\circ}$ to $71^{\circ} \mathrm{Cat} 90 \mathrm{~mm}$, $\left.n_{D}^{20}=1.4299\right)$. Although there was no appreciable forerun, a large amount of high-boiling material $\left(175^{\circ}\right.$ to $\left.200^{\circ} \mathrm{C}\right)$ was present. This material was not identified, but is presumed to be polymers (dimers and trimers) of the alkadiene, formed under the influence of the Grignard reagent.

The crude 2,3,5-trimethyl-2-hexene contained a considerable quantity of chloride, the greater part of which was removed by boiling with alcoholic potassium hydroxide. Hydrogenation of the crude alkene gave 2,3,5-trimethylhexane, which was filtered through silica gel and distilled in column 3. From $2,500 \mathrm{ml}$ of material there was obtained $900 \mathrm{ml}$ that boiled at $131.9^{\circ} \mathrm{C}\left(n_{D}^{20}=\right.$ 1.4060 to 1.4061 ) and $50 \mathrm{ml}$ of a hydrocarbon t boiled at $141.9^{\circ} \mathrm{C}\left(n_{D}^{20}=1.4218\right)$. The latter was identified as 2,3,3,4-tetramethylpentane by comparison with a sample prepared in another manner. A residue of about 1 liter that boiled above $165^{\circ} \mathrm{C}$ resulted from this distillation. This residue was probably formed by the action of potassium hydroxide or hydrogenation catalyst on the unsaturated halide which was in the crude olefin. Obviously, most of the Grignard reagent was dissipated in side reactions rather than by coupling with the chloride in the expected manner. This tendency could possibly have been decreased by carrying out the reaction in a more dilute solution.

This preparation was made in 1939 , at the suggestion of C. E. Boord, Ohio State University. The goal was the preparation of 2,3,5-trimethylhexane and 2,3,3,4-tetramethylpentane. The reaction yielded about 18 parts of the former to 1 part of the latter. These two hydrocarbons prob- 
ably resulted from the action of the Grignard reagent on two isomers of 2,3-dimethylchlorobutenes. These two isomers, probably were 1-chloro2,3-dimethyl-2-butene, formed by 1,4 addition of hydrogen chloride to the diolefin, and 3 -chloro2,3,-dimethyl-1-butene, formed by 1,2 addition. The former chloride would be expected to react with isopropylmagnesium chloride to give 2,3,5trimethyl-2-hexene, and the latter chloride to give 2,3,3,4-tetramethyl-1-pentene.

E. T. Cline [10] has made a study of this reaction, in which hydrogen bromide, rather than hydrogen chloride, was used. He obtained a ratio of alkenes of 1.6 parts of 2,3,5-trimethyl-2-hexene to 1 part of 2,3,3,4-tetramethyl-1-pentene.

\section{2,2,4-Trimethylhexane}

In 1937 Brooks, Cleaton, and Carter [4] isolated an unknown nonane from the residue obtained in the distillation of isooctane (2,2,4-trimethylpentane), which was tentatively identified as $2,2,4$ trimethylhexane. In order to establish the identity of this hydrocarbon, a sample of 2,2,4trimethylhexane has been prepared, and a comparison of physical properties has been made.

Diisobutylene was oxidized by sodium dichromate as described by Whitmore, Homeyer, and Trent [37] to give trimethylacetic acid and 4,4-dimethyl-2-pentanone (methylneopentyl ketone). (The oxidation of diisobutylene isomers is discussed more fully in sections IV-22 and 23.)

To 7.0 moles of ethylmagnesium chloride in $1,400 \mathrm{ml}$ of ether solution was added $742 \mathrm{~g}(6.5$ moles) of 4,4-dimethyl-2-pentanone (bp $124^{\circ} \mathrm{C}$ at $760 \mathrm{~mm} \mathrm{Hg}, n_{D}^{20}=1.4038$ ) in $800 \mathrm{ml}$ of dry ether. The reaction mixture was allowed to stand at room temperature for $35 \mathrm{hr}$, refluxed for $6 \mathrm{hr}$, and then worked up in the standard manner. The organic material was washed, dried, and distilled in column 4. In addition to ether and recovered ketone, $409 \mathrm{~g}$ (2.9 moles) of 3,5,5-trimethyl-3-hexanol, and $84 \mathrm{~g}$ (0.6 mole) of nonenes resulting from premature dehydration of the carbinol were obtained. The purified carbinol was dehydrated by heating with $\beta$-naphthalene sulfonic acid (1 g) to give a mixture of alkenes that boiled $127^{\circ}$ to $132^{\circ} \mathrm{C}$. The yield was $335 \mathrm{~g}$ $(91 \%)$. This alkene mixture has been analyzed by Whitmore and Cook [35], who found by ozonolysis that it contained approximately 3 parts of 3,5,5-trimethyl-2-hexene, 1 part of 2-ethyl-4,4-dimethyl-1-pentene, and a trace of 3,5,5-trimethyl-3-hexene. All these compounds give the same alkane when hydrogenated, so no attempt was made to separate them.

The alkenes were hydrogenated, and the product filtered through silica gel and distilled in column 5. The middle 70 percent of the distillate, which distilled at a constant temperature, was redistilled in the same column; the middle 25 percent of the distillate from the latter distillation was used in the measurement of physical properties. The properties of the synthetic material are given in table 6 and are compared with those of the compound isolated by Brooks, et al. in table 4. The identity of the two is proved by data on the freezing point of the 50:50 mixture.

TABLE 4.-Properties of 2,2,4-trimethylhexane

\begin{tabular}{|c|c|c|}
\hline Property & $\begin{array}{l}\text { Synthetic } \\
\text { material } \\
\text { 2,2,4-trimethyl- } \\
\text { hexane }\end{array}$ & $\begin{array}{l}\text { Fraction from } \\
\text { isooctane } \\
\text { residue [4] }\end{array}$ \\
\hline $\begin{array}{l}\text { Boiling point at } 760 \mathrm{~mm} \mathrm{Hg},{ }^{\circ} \mathrm{C} \\
\text { Change in boiling point with pressure, } \\
{ }^{\circ} \mathrm{C} / \mathrm{mm} \mathrm{Hg}\end{array}$ & $\begin{aligned} 126.54 \\
0.0503\end{aligned}$ & 126.51 \\
\hline $\begin{array}{l}\text { Freezing point, }{ }^{\circ} \mathrm{C} \\
\text { Freezing point of mixture, }{ }^{\circ} \mathrm{C}\end{array}$ & $\begin{array}{r}-123.4(\mathrm{mp}) \\
-12\end{array}$ & $4.19^{-129.53}$ \\
\hline Refractive index $\left\{\begin{array}{l}n_{D}^{20} \ldots \ldots \\
n_{D}^{25} \ldots \ldots\end{array}\right.$ & \begin{tabular}{l|}
1.4033 \\
1.4010
\end{tabular} & 1. 40312 \\
\hline Density, $\mathrm{g} / \mathrm{ml}\left\{\begin{array}{l}D^{20} \ldots \ldots \\
D^{25} \ldots\end{array}\right.$ & $\begin{array}{r}0.7156 \\
.7118\end{array}$ & $0.7153^{\mathrm{a}}$ \\
\hline
\end{tabular}

a The published density (0.7048) [4] of the material isolated from "is ovetane residue" is in error. A recalculation of the original data gave 0.7153 ; redetermination gave 0.7154

\section{2,2-Dimethyl-3-ethylpentane}

The synthesis of 2,2-dimethyl-3-ethylpentane was carried out in the following steps: (a) Reaction of $t$-butylmagnesium chloride with carbon dioxide to give the "Grignard complex" of trimethylacetic acid, (b) reaction o this complex with ethylmagnesium chloride to produce 2,2dimethyl-3-ethyl-3-pentanol, (c) dehydration of the carbinol to 4,4-dimethyl-3-ethyl-2-pentene, and (d) hydrogenation of the olefin to 2,2 dimethyl-3-ethylpentane.

To 50.2 moles of $t$-butylmagnesium chloride in 18 liters of ether, cooled to $5^{\circ} \mathrm{C}$, was added $3 \mathrm{~kg}$ of solid carbon dioxide in small pieces while the reaction mixture was being stirred. Stirring was continued while the mixture came to room temperature and while it was heated to reflux for $2 \mathrm{hr}$. It was then cooled, and 104 moles of ethylmagnesium chloride in 20 liters of ether was added 
slowly. After addition was complete, the mixture was stirred for $6 \mathrm{hr}$ and allowed to stand at room temperature for 2 days. The product was distilled in column 6. From this distillation was obtained $3,485 \mathrm{~g}\left(48.2 \%\right.$ yield) of carbinol (bp $90^{\circ}$ to $95^{\circ} \mathrm{C}$ at $50 \mathrm{~mm} \mathrm{Hg}, 171^{\circ}$ to $176^{\circ} \mathrm{C}$ at $756 \mathrm{~mm} \mathrm{Hg}$, $n_{D}^{20}=1.4417, d^{20}=0.851$ ). The carbinol was dehydrated by heating with $\beta$-naphthalene sulfonic acid to give $3,600 \mathrm{ml}$ of alkene. Fractionation of the crude alkene in column 5 gave $2,680 \mathrm{ml}$ of purified 4,4-dimethyl-3-ethyl-2-pentene. The alkene was hydrogenated and the product filtered through silica gel and distilled in column 1. From this distillation $1,650 \mathrm{ml}$ of constant-boiling 2,2dimethyl-3-ethylpentane $\left(n_{D}^{20}=1.41225\right.$ to 1.41230$)$ was obtained.

\section{2,4-Dimethyl-3-ethylpentane}

Preparation of 2,4-dimethyl-3-ethylpentane was accomplished by hydrogenation of the alkenes that resulted from the dehydration of 2,4-dimethyl3-ethyl-3-pentanol. The carbinol resulted from the action of ethylmagnesium chloride on 2,4dimethyl-3-pentanone (diisopropyl ketone).

To 76.2 moles of ethylmagnesium chloride was added 75 moles of 2,4-dimethyl-3-pentanone during 2 days. The product was recovered by addition of ice and ammonium chloride to the reaction mixture, and by subsequent distillation gave $5,650 \mathrm{~g}$ $(52.3 \%)$ of 2,4-dimethyl-3-ethyl-3-pentanol. A pure sample was obtained by redistillation of the best portion of the crude.

The carbinol was dehydrated with $\beta$-naphthalene sulfonic acid to give $6,110 \mathrm{ml}$ of crude alkene mixture. A charge of 2 liters of the dehydration product was fractionated in column 5 for analysis. The individual olefins were recovered in the ratio of 77 percent of the lower-boiling 2, 4-dimethyl-3ethyl-2-pentene to 23 percent of the higherboiling 4-methyl-3-isopropyl-2-pentene. A sample of each of these isomers was redistilled for determination of pbysical constants. The values obtained were:

\begin{tabular}{|c|c|c|}
\hline & $\begin{array}{l}\text { 2, 4-Dimethyl- } \\
\text { 3-ethyl-2- } \\
\text { pentene }\end{array}$ & $\begin{array}{l}\text { 4-Methyl-3- } \\
\text { isopropyl-2- } \\
\text { pentene }\end{array}$ \\
\hline $\begin{array}{l}\text { Boiling point at } 760 \mathrm{~mm} \mathrm{Hg}\left({ }^{\circ} \mathrm{C}\right) \\
\text { Refractive index }\left\{\begin{array}{l}n_{D}^{20} \\
n_{D}^{25}\end{array}\right. \\
\text { Deusity }\left\{\begin{array}{l}d^{20} \\
d^{25}\end{array}\right.\end{array}$ & $\begin{array}{r}130.5 \\
1.4227 \\
1.4204 \\
0.7433 \\
.7385\end{array}$ & $\begin{array}{r}138.7 \\
1.4349 \\
1.4326 \\
0.7584 \\
.7550\end{array}$ \\
\hline
\end{tabular}

Hydrogenation of samples of both alkenes yielded the same alkane. The alkene mixture (bp $128^{\circ}$ to $140^{\circ} \mathrm{C}$ ) was hydrogenated and the resulting product distilled in column 4. The portion boiling $136^{\circ}$ to $139^{\circ} \mathrm{C}$ was filtered through silica gel and refractionated in column 1.

In 1945 the preparation was repeated on a somewhat larger scale. For this preparation, 2,4-dimethyl-3-pentanone was fractionated in still 11. Only the purest fractions obtained (bp $124.6^{\circ}$ to $124.7^{\circ} \mathrm{C}, n_{D}^{20}=1.4015$ to 1.4017 ) were used in the subsequent synthesis. The carbinol was the product of reaction of the Grignard reagent prepared from 260 moles of ethyi chloride with 223 moles of redistilled ketone. The reaction product was distilled in column 21 until the head temperature was $130^{\circ} \mathrm{C}$. A sample (1,600 g) of the residue was distilled in column 4 . From this distillation there was obtained $1,130 \mathrm{~g}$ of pure carbinol (2,4-dimethyl-3-ethyl-3-pentanol) (bp $94.5^{\circ}$ to $95.0^{\circ} \mathrm{C}$ at $47 \mathrm{~mm} \mathrm{Hg}$ ) and about $200 \mathrm{~g}$ of less pure material. A sample from the heart of this distillation was reserved for physical-constant measurements.

The rest of the undistilled residue was dehydrated with $\beta$-naphthalene sulfonic acid, and the dehydration products were washed, dried, and distilled in column 11. Analysis of the distillation curve showed the presence of 77 volume percent (13.4 liters) of lower-boiling olefin, and 23 volume percent (4.0 liters) of the higher-boiling isomer. In this distillation a best sample from each of the plateaus was reserved and redistilled in column 17 for physical-constant measurements.

Hydrogenation of the olefins was carried out as previously described. The paraffin was fractionated in columns 17, 18, 19, and 20. There was obtained $11,800 \mathrm{ml}$ of pure hydrocarbon for engine tests.

Physical constants of materials synthesized in this later preparation are given in table 6 .

\section{8, 2,2,3,3-Tetramethylpentane (Tetrane)}

The synthesis of 2,2,3,3-tetramethylpentane (a new compound, named tetrane) involved (a) preparation of 2,3,3-trimethyl-2-butanol(triptanol) from 3,3-dimethyl-2-butanone (pinacolone) and methylmagnesium bromide, (b) reaction of this carbinol with hydrochloric acid to give 2-chlor-2,3,3trimethylbutane (triptyl chloride), and (c) reaction of the chloride with ethylmagnesium chloride to 
give the nonane and 2,3,3-trimethyl-1-butene (triptene).

From 82 moles of pinacolone and 84 moles of methylmagnesium bromide, 56.5 moles of 2,3,3trimethyl-2-butanol was prepared. This carbinol was dissolved in ether, and the solution was shaken with several portions of concentrated hydrochloric acid. Samples of the ether solution were removed periodically. The sublimation point of the crude chloride from these samples rose to $131^{\circ}$ to $133^{\circ} \mathrm{C}$. Recystallized chloride was found to sublime at $133^{\circ} \mathrm{C}$. The chloride solution was washed, dried, and added to 115 moles of ethylmagnesium chloride. The mixture was stirred for $3 \mathrm{hr}$ and then allowed to stand for 4 weeks at room temperature.

After the reaction mixture was worked up, the organic material was distilled in column 6 , and yielded 2,100 $\mathrm{ml}$ of recovered triptene (trimethylbutene) and 1,900 $\mathrm{ml}$ of crude 2,2,3,3-tetramethylpentane, which was contaminated by a considerable amount of triptanol. The carbinol was filtered off as the hydrate, and the filtrate was dried and filtered through silica gel. The volume of nonane recovered was $1,250 \mathrm{ml}$, which represents a yield of 9 percent, based on the original pinacolone. Distillation of this material in column 4 gave $1,087 \mathrm{ml}$ of hydrocarbon, which was collected at $88.6^{\circ}$ to $88.7^{\circ} \mathrm{C}$ at $159 \mathrm{~mm} \mathrm{Hg}$. A portion of this material was recrystallized repeatedly, until the refractive index and freezing point were unchanged by further crystallization. Physical constants were determined on this sample.

A second run of this preparation was made later, in which recrystallized triptyl chloride was reacted with an equimolar quantity of the Grignard reagent. In this case the yield was increased to 22 percent, based on the chloride.

On authority of the National Advisory Committee for Aeronautics, procurement of 10 gallons of this hydrocarbon was undertaken in 1941 . Part of this (2.9 gallons) was prepared at Ohio State University under NACA contract. The rest was prepared at the Bureau. This large-scale preparation was carried out by a modification of the technic developed at Ohio State University (C. E. Boord and K. W. Greenlee) as a part of the NACA contract. The chloride was added to the Grignard reagent in eight equal portions, in 8 successive days, while the reaction mixture was kept at $35^{\circ} \mathrm{C}$. No coupling catalyst was used. (Iodine was used at O. S. U.)
An improved method was devised for the preparation of the large quantities of triptyl chloride necessary for this synthesis. The equipment consisted of three reactors, made from 30in. lengths of 12 -in. pipe, closed at both ends with companion and blind flanges. One end of each reactor was fitted with a small steel valve ( $1 / 4 \mathrm{in}$.). These reactors were refrigerated $\left(-30^{\circ} \mathrm{C}\right)$ and were connected to a manifold through which hydrogen chloride could be admitted to each. The reactors were charged with triptene in widemouthed bottles and mason jars. The flanges of the reactors were secured by bolts, and the reactors were allowed to stand until cold. Hydrogen chloride was then admitted until the pressure was 100 to $120 \mathrm{lb} / \mathrm{in}^{2}$. The pressure gradually fell as the gas reacted until the pressure was about 50 to $60 \mathrm{lb} / \mathrm{in}^{2}$. Then the process was repeated until there was no appreciable change in pressure during $1 \mathrm{hr}$. The excess gas was released, the system purged with dry air, and the product removed. The yield was practically quantitative. The product was uncolored and contained a small amount of excess hydrogen chloride. This excess was converted to alkyl chloride by adding a small amount of olefin to each jar and allowing to stand until reacted. By means of this technic, 20 to 35 liters of triptene was converted to the chloride in 1 working day. The triptene for this work was kindly supplied by the General Motors Research Laboratories, through the courtesy of T. A. Boyd and W. G. Lovell.

To 300 moles of ethylmagnesium chloride there was added 300 moles of triptyl chloride in eight equal portions during 8 days. During this time, the reaction mixture was heated to reflux temperature and stirred. At the end of 2 to 4 additional days, when all of the Grignard reagent had reacted, the mixture was worked up with ice and hydrochloric acid and washed four times with water. Distillation of the ether, and of most of the triptene, was carried out from the reaction kettle. The distillate was dried and redistilled in column 12 or 13 for recovery of triptene.

The residue in the reaction kettle was boiled with sodium propylate in propyl alcohol until the product was substantially free of chloride. After the product was washed, it was steam distilled, and the distillate dried and boiled with alcoholic silver nitrate to remove the last traces of chloride. 
Then the product was filtered, washed several times, dried, and distilled in columns 11, 18, 19, and 20 .

From two runs as described above, which were worked up together, there was obtained 14.92 $\mathrm{kg}$ (116.6 moles) of tetrane, which was 99.6 mole percent pure. This represents a yield of 19.4 percent. A total of $21.7 \mathrm{~kg}$ was prepared by this method.

\section{2,2,3,4-Tetramethylpentane and 2,3,3,4-Tetramethylpentane}

Thd first preparation of these two nonanes was accomplished by hydrogenation of the alkenes [38] formed by the dehydration of 2,2,3,4-tetramethyl-3-pentanol. The carbinol was prepared by the reaction between methylmagnesium bromide and 2,2,4-trimethyl-3-pentanone. This ketone was the result of oxidation of 2,2,4-trimethyl3-pentanol, one of the products resulting from the action of $t$-butylmagnesium chloride on isobutyraldehyde.

2,2,4-Trimethyl-3-pentanol was prepared by the method of Whitmore and Laughlin [38]. To 55 moles of $t$-butylmagnesium chloride was added $3,960 \mathrm{~g}$ (55 moles) of isobutyraldehyde. Distillation of the organic reaction products gave 4,290 g (33 moles, 60\% yield) of 2,2,4-trimethyl-3pentanol. The carbinol was oxidized to pentamethylacetone (2,2,4-trimethyl-3-pentanone) with potassium dichromate and sulfuric acid, by the method of Faworsky [15]. From 32 moles of carbinol there was obtained $3,150 \mathrm{~g}$ (24.6 moles, $77 \%$ yield) of ketone, which was distilled in column 5.

The 2,2,4-trimethyl-3-pentanone (24.6 moles) in 6 liters of ether was reacted with 26 moles of methylmagnesium bromide, and the product was distilled in column 5 until the temperature reached $143^{\circ} \mathrm{C}$. At this point dehydration of the carbinol was beginning to take place, so the distillation was interrupted, and the clear, slightly yellow residue $(2,950 \mathrm{ml})$ was dehydrated with $\beta$-naphthalene sulfonic acid.

From the dehydration there resulted 2,410 $\mathrm{ml}$ of alkene mixture, which was dried and distilled in column 3. The following fractions were obtained:

\begin{tabular}{|c|c|c|c|}
\hline Fraction & $\begin{array}{l}\text { Boiling } \\
\text { range }\end{array}$ & & Volume \\
\hline $\begin{array}{l}1 \\
2 \ldots \ldots \\
3 \\
4 \\
5\end{array}$ & $\begin{array}{l}\circ C \\
91 \text { to } 119 \\
119 \text { to } 124 \\
124 \text { to } 129 \\
130 \text { to } 135 \\
>135\end{array}$ & $\begin{array}{r}23 \\
1,550 \\
200 \\
600 \\
120\end{array}$ & $\begin{array}{l}\text { forerun. } m l \\
\text { 3,3-dimethyl-2-isopropyl-1-butene. } \\
\text { intermediate. } \\
\text { 2,3,3,4-tetramethyl-1-pentene. } \\
\text { residue. }\end{array}$ \\
\hline
\end{tabular}

Fractions 2, 3, and 4 represents a combined yield of alkenes of 15.9 moles $(65 \%$, based on $2,2,4-$ trimethyl-3-pentanone). Samples from the middle of the plateaus represented by fractions 2 and 4 were reserved for physical-constant measurements. No attempt was made to isolate 2,3,4,4tetramethyl-2-pentene, a very small quantity of which was found by Whitmore and Laughlin [38].

The alkene fraction, which distilled at $119^{\circ}$ to $124^{\circ} \mathrm{C}$, was hydrogenated, and the product was filtered through silica gel and distilled in column 3. There was obtained $1,070 \mathrm{ml}$ of hydrocarbon, which boiled $133.7^{\circ}$ to $134.1^{\circ} \mathrm{C}$, $n_{D}^{20}($ uncorrected $)=1.4147$ to 1.4150 . Redistillation of this material gave $930 \mathrm{ml}$ collected at $133.8^{\circ} \mathrm{C}$. Physical constants were determined on a sample from the center of this fraction.

Alkene fraction 4 was treated in like manner, and yielded $347 \mathrm{ml}$ of material collected at $142^{\circ} \mathrm{C}$ (uncorrected), fractions of which showed a refractive index range, $n_{D}^{20}$ (uncorrected) of 1.4219 to 1.4220 A sample from this distillation was reserved for determination of physical constants.

All intermediate fractions, foreruns, residues, and material eluted from silica gel were hydrogenated and distilled in column 8 . In this way there was obtained an additional $200 \mathrm{ml}$ of 2,2,3,4-tetramethylpentane and $145 \mathrm{ml}$ of 2,3,3,4tetramethylpentane.

Tests on these two hydrocarbons demonstrated the advisability of preparing larger quantities. Consequently, 10 gallons of each was synthesized at Pennsylvania State College, under the direction of Frank C. Whitmore, by contract with the NACA.

These hydrocarbons were purified in these laboratories for engine tests by distillation in column 1. New pure samples for measurement of physical constants were obtained concurrently. 


\section{Dimethyl Zinc Synthesis of Three Tetramethylpentanes}

The syntheses of three tetramethylpentanes are described in the preceding sections. In the spring of 1942 considerable interest was developed in dimethyl zinc syntheses. It was demonstrated that the engine characteristics of a fuel derived from butene co-dimer could be considerably improved by the introduction of tetramethylpentanes. This was first accomplished by synthesis of these nonanes in situ. An olefin co-polymer fraction containing 3,4,4-trimethyl-2-pentene and 2,3,4trimethyl-2-pentene was reacted with dry hydrogen chloride until about 60 percent of the olefin was converted to chloride. This chloride-olefin mixture was treated with dimethyl zinc in a solvent of hydrogenated co-dimer, which contained 2,2,3- and 2,3,4-trimethylpentanes. The resultant product was hydrogenated to a mixture of hydrocarbons, all known to have superior characteristics.

This study led to the syntheses of these compounds in a pure state by this method.

Secondary and tertiary butyl alcohols were copolymerized in the presence of sulfuric acid in the manner described by Whitmore, Laughlin, Matuszeski, and Surmatis [39]. A portion of the product was analyzed by distillation in column 1 and was found to contain the "diisobutylenes", (2,4,4trimethyl-1-and 2-pentenes) (25\%), 3,4,4-trimethyl-2-pentene (23\%), 2,3,4-trimethyl-2-pentene $(37 \%)$, and higher-boiling material $(15 \%)$. The rest of the olefin mixture was roughly separated by distillation in column 5 . The fractions which boiled $107^{\circ}$ to $120^{\circ} \mathrm{C}$ amounted to $9,740 \mathrm{~g}$, and consisted of 2,3,4-trimethyl-2-pentene and 3,4-4-trimethyl-2pentene as major components. Part of this fraction $(6,300 \mathrm{~g})$ was fractionated in column 2. By this distillation there was obtained 1,150 $\mathrm{g}$ of 3,4,4-trimethyl-2-pentene $\left(n_{D}^{2)}=1.4230, \quad n_{D}^{25}=1,4205, \quad D^{20}=\right.$ $0.7392, D^{25}=0.7350$, bp $112.1^{\circ}$ to $112.8^{\circ} \mathrm{C}$ ) and $1,865 \mathrm{~g}$ of 2,3,4-trimethyl-2-pentene $\left(n_{D}^{20}=1,4275\right.$, $n_{D}^{25}=1,4250, D^{20}=0.7434, D^{25}=0.7391$, bp $116.3^{\circ}$ to $\left.116.5^{\circ} \mathrm{C}\right)$.

These two alkenes were reacted separately with hydrogen chloride at $-60^{\circ} \mathrm{C}$ in an apparatus previously described [19] (also section IV-3) until approximately 60 percent of the alkene had been converted to alkyl chloride. The products were washed, dried, and fractionated in column 3 . In this way, $716 \mathrm{~g}$ of constant-boiling 3-chloro2,2,3-trimethylpentane was obtained from the 3,4,4-trimethyl-2-pentene. The chloride from 2,3,4-trimethyl-2-pentene $(1,410 \mathrm{~g})$ was probably a mixture of 2-chloro-2,3,4-trimethylpentane and 3-chloro-2,3,4-trimethylpentane. As these two chlorides were expected to yield two different nonanes (by reaction with dimethyl zinc) which have boiling points differing by about $8^{\circ} \mathrm{C}$, no attempt was made to separate the chloride mixture. Physical constants measured on the chlorides are included in table 6 .

\section{(a) 2,2,3,3-Tetramethylpentane}

In the apparatus, and by the technic described in section IV-3, 4.15 moles (614 g) of 3-chloro2,2,3-trimethylpentane in $700 \mathrm{ml}$ of isooctane (2,2,4-trimethylpentane, S-4 reference fuel) were allowed to react with the dimethyl zinc from 7.75 moles of methyl iodide. The dimethyl zinc was in a solution with $500 \mathrm{ml}$ of "isooctane". The bath temperature for the reaction was $7^{\circ} \mathrm{C}$. The product was boiled for $2 \mathrm{hr}$ with 5 percent potassium hydroxide in alcohol, washed, and fractionated in column 4 . This distillation gave:

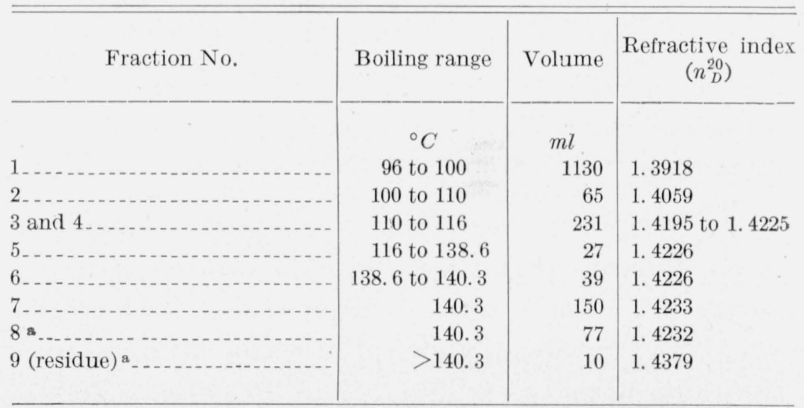

a Distillation of the residue from fraction 7 was continued in still 8 and. gave the values shown.

Fraction 1 was recovered solvent. Alkene byproducts of the reaction, formed by dehydrochlorination of the alkyl chloride, were contained in fractions 2 to 5. By the low refractive indices of these fractions, it is indicated that this material consisted mostly of 3,4,4-trimethyl-2-pentene. The yield of 2,2,3,3-tetramethylpentane (fractions 6,7 , and 8) amounted to 37.7 percent based on alkyl chloride. Fraction 7, after filtration through silica gel, had the following properties: Freezing point, $-11.85^{\circ} \mathrm{C}$; boiling point, $140.20^{\circ}$ to $140.23^{\circ} \mathrm{C}$ 
at $760 \mathrm{~mm} \mathrm{Hg}$; refractive index, $n_{D}^{20}=1.4233$, $n_{D}^{25}=1.4211 ; \quad$ density $, \quad d^{20}=0.7565, \quad d^{25}=0.7527$. It may be seen that the product was of high purity, when these properties are compared with those of the pure sample, as listed in table 6 . The freezing point indicates a purity of about 99.5 mole percent.

\section{(b) 2,2,3,4- and 2,3,3,4-Tetramethylpentanes}

By using the same procedure described above, two runs were made in which a total of 8.35 moles of the mixture of 2-, and 3-chloro-2,3,4-trimethylpentanes was reacted, at $10^{\circ} \mathrm{C}$, with the dimethyl zinc from 15.5 moles of methyl iodide. The combined products were refluxed with alcoholic potassium hydroxide, washed, dried, and distilled in column 4. This operation gave:

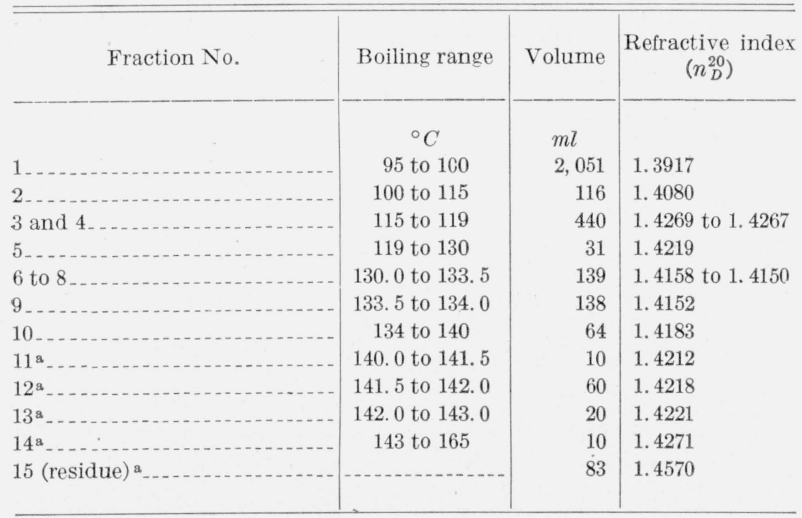

a The residue was distilled in still 8 , and gave the values shown.

Fraction 1 was recovered "isooctane," fractions 3 and 4 were alkene byproducts, indicated to be mostly 2,3,4-trimethyl-2-pentene by the refractive indices. The total yield of tetramethylpentanes (fractions 6 to 14) amounted to 30 percent, based on alkyl chloride. These tetramethylpentanes consisted of about 71 percent of 2,2,3,4-tetramethylpentane and about 29 percent of $2,3,3,4$ tetramethylpentane.

Fraction 9, after filtration through silica gel, had the following properties: Freezing point, $-122.54^{\circ} \mathrm{C}$; boiling point $133.3^{\circ}$ to $133.4^{\circ} \mathrm{C}$ at $760 \mathrm{~mm} \mathrm{Hg}$; refractive index, $n_{D}^{20}=1.4148, n_{D}^{25}=$ 1.4127; density, $d^{20}=0.7397, d^{25}=0.7358$. These values are in agreement with those reported for the pure 2,2,3,4-tetramethylpentane (table 6).

Fraction 12 was filtered through silica gel, and the eluent was used for the measurement of physical properties. The following properties were found: Boiling point, $141.3^{\circ}$ to $141.4^{\circ} \mathrm{C}$ at $760 \mathrm{~mm} \mathrm{Hg}$; refractive index, $n_{D}^{20}=1.4217, n_{D}^{25}=$ 1.4196; density, $d^{20}=0.7545, d^{25}=0.7512$. These data agree with those reported for purer 2,3,3,4tetramethylpentane in table 6 .

A tetramethylpentane, assumed to be 2,3,3,4tetramethylpentane, was prepared by Dinerstein [11] in 1940, by action of dimethyl zinc on " 3 chloro-2,3,4-trimethylpentane." Later work [14, 31] shows that the hydrocarbon prepared by Dinerstein was 2,2,3,4-tetramethylpentane.

\section{2,4-Dimethyl-3-isopropylpentane (Triisopropyl- methane)}

The recent preparations of triisopropylcarbinol by the action of isopropyl lithium on 2,4-dimethyl3-pentanone (diisopropyl ketone) [42], and by the action of isopropyl chloride on diisopropyl ketone in the presence of sodium [3], have made available a method for synthesizing triisopropylmethane (2,4-dimethyl-3-isopropylpentane). A quantity of this compound has been prepared by the use of isopropyl lithium.

Preliminary work on this reaction was performed in several small-scale experiments, in each of which 10 gram atoms of lithium, 6.5 moles of isopropyl chloride, 5.4 moles of diisopropyl ketone, and $2,000 \mathrm{ml}$ of solvent were used. During this study, it was found that technical 2,2,4-trimethylpentane (isooctane) served admirably as a solvent when its use was augmented by efficient stirring and external cooling of the reaction mixture. No preliminary purification of the solvent was necessary, and the hazards accompanying its use are much less than those of the petroleum ether used by the original investigators [42].

The preparation of the considerable quantities of finely divided lithium required was expedited by the use of a small laboratory rolling mill. While the lithium was being worked in the mill it was lubricated and coated with a mixture of 80 percent isooctane and 20 percent light mineral oil applied by means of an oil can. This technic tended to prevent the lithium from sticking to the rolls and also prevented excessive oxide formation. The rolled pieces, about $0.003 \mathrm{in}$. thick, were cut into ribbons and then into squares in a large shallow pan under isooctane.

The yields in all the preliminary runs amounted to 18 to 22 percent of carbinol. No appreciable change in yield was experienced when the reaction 
between isopropyl lithium and diisopropyl ketone was carried out at $99^{\circ} \mathrm{C}$, the temperature of boiling isooctane, rather than at $35^{\circ} \mathrm{C}$, the temperature used by the original investigators.

After the technic of handling the reaction had been sufficiently developed, a large run was carried out in the 50-gallon stainless-steel kettle. The total quantity of reactants used were: $159 \mathrm{~g}$ atoms $(1.10 \mathrm{~kg})$ of lithium, 115 moles $(9.03 \mathrm{~kg})$ of isopropyl chloride, 80 moles $(9.13 \mathrm{~kg}$ ) of diisopropyl ketone, and 55 liters of isooctane. The quantity of isopropyl chloride was relatively larger than that used by the original investigators in order that a minimum amount of lithium be left unreacted, and to compensate for possible loss through the reflux condenser. The diisopropyl ketone was constant-boiling material obtained by redistillation of the commercial product in still 11 .

The kettle was flushed with nitrogen and charged with 31 liters of isooctane. About half the lithium was added and the reaction started by the addition of 1 liter of isopropyl chloride in 1 liter of isooctane and by warming the jacket to $35^{\circ} \mathrm{C}$. The remainder of the lithium was added in three additional charges during the next $2 \frac{1 / 2}{2}$ days. During the first 3 days, a mixture of the remainder of the isopropyl chloride in an equal volume of isooctane was added in four charges.

A solution of diisopropyl ketone in 11.4 liters of isooctane was added during $8 \mathrm{hr}$, while the reaction temperature was held at $45^{\circ}$ to $60^{\circ} \mathrm{C}$. After addition was complete, the mixture was warmed and stirred for $5 \mathrm{hr}$, after which it was cooled. Decomposition of the reaction mixture was effected by the addition of 25 pounds of cracked ice, followed by a solution of 11 pounds of ammonium chloride in 5 gallons of water. The aqueous layer was removed, and the organic layer washed five times, each time with 3 to 5 gallons of water, after which it was withdrawn and dried overnight with potassium carbonate.

Fractionation of the product in column 6 gave: recovered isooctane; diisopropyl ketone, bp $121^{\circ}$ to $126^{\circ} \mathrm{C}, 2,355 \mathrm{~g}$; intermediate fractions, $240 \mathrm{~g}$; and triisopropylcarbinol, bp $104^{\circ}$ to $110^{\circ} \mathrm{C}$ at 50 to $55 \mathrm{~mm} \mathrm{Hg}, 2,576 \mathrm{~g}$. This represents a yield of 20.4 percent, based on the diisopropyl ketone added. A part of the triisopropylcarbinol was redistilled and a pure sample collected from the middle of this distillation for the measurement of physical constants.
The carbinol was dehydrated by distillation from anhydrous copper sulfate. From 16 moles of triisopropylcarbinol, 14.4 moles $(90 \%)$ of crude 2,4-dimethyl-3-isopropyl-2-pentene was obtained. Water recovery amounted to 80 percent. The crude olefin was dried over calcium chloride and distilled in column 6 , from which $1,372 \mathrm{~g}$ of material that boiled $153.2^{\circ}$ to $153.6^{\circ} \mathrm{C}$ at 756 to 759 $\mathrm{mm} \mathrm{Hg}, n_{D}^{20}=1.4368$ to 1.4371 (all values uncorrected) was collected. A sample was removed from the middle of the distillation for the measurement of physical constants.

The olefin was hydrogenated, and distilled in column 6, and gave $1,100 \mathrm{~g}(80 \%)$ of "constantboiling material;" bp $156.5^{\circ} \mathrm{C}$ at $749 \mathrm{~mm}$. Hg; $n_{D}^{20}=1.4234-1.4236$ (all values uncorrected). This material contained a trace of olefin, which was removed by repeated filtration through silica gel. Refractionation under reduced pressure afforded the means of obtaining a pure sample for physical-constants measurements.

\section{Pentamethylpentanes}

\section{(a) 2,2,3,3,4-Pentamethylpentane}

The first preparation of 2,2,3,3,4-pentamethylpentane was carried out by the reaction between 2-chloro-2,3,3-trimethylbutane and isopropylmagnesium chloride.

To 30.5 moles of isopropylmagnesium chloride in 10.53 liters of ether solution there was added, at room temperature, 26.4 moles of 2-chloro-2,3,3trimethylbutane (sublimation point $132.7^{\circ}$ to $134^{\circ} \mathrm{C}$ ) in 3.5 liters of ether. After standing for 3 weeks at $15^{\circ}$ to $20^{\circ} \mathrm{C}$, the reaction mixture was worked up in the usual manner. The product, distilled in column 6 , gave 14.8 moles of $2,3,3-$ trimethyl-1-butene, formed by dehydrochlorination of 2-chloro-2,3,3-trimethylbutane; 0.1 mole of 2-propanol, formed by oxidation of the Grignard reagent found in an azeotrope with 2,3,3-trimethyl1-butene; 2.2 moles of recovered 2-chloro-2,3,3trimethylbutane; 3.1 moles of 2,3,3-trimethyl-2butanol, presumably by hydrolysis of the chloride; and 1.05 moles of crude 2,2,3,3,4-pentamethylpentane. This represents a yield of 4.0 percent. Another run, in which 19.3 moles of the chloride was used, and which was kept at $5^{\circ} \mathrm{C}$ for 3 weeks, then at room temperature for 2 weeks, yielded 0.6 mole of additional crude (3.1 percent yield).

The combined yield of crude material $(300 \mathrm{ml})$ was fractionated in column 8 . From this distilla- 
tion there was obtained $226 \mathrm{ml}$ of material that boiled at $163.7^{\circ}$ to $164^{\circ} \mathrm{C}$ (uncorrected). This product was redistilled in the same column, and there was collected $186 \mathrm{ml}$ of constant-boiling, constant-refractive index material. The physical constants of this product, after filtration through silica gel were as follows: $\mathrm{fp}-37.5^{\circ} \mathrm{C}, n_{D}^{20}=1.4361$, $d^{20}=0.7803$, bp $165.54^{\circ}$ to $165.56^{\circ} \mathrm{C}$ at $750.5 \mathrm{~mm}$ $\mathrm{Hg}$.

Later, two other methods for the preparation of this decane were investigated. Both of these methods involved the methylation of 3-chloro2,2,3,4-tetramethylpentane. This chloride was prepared in good yield from the corresponding alcohol by reaction with concentrated hydrochloric acid. The chloride decomposed easily when a boiling-point determination was attempted at atmospheric pressure. It would not crystallize at dry-ice temperature and had an index of refraction $\left(n_{D}^{20}\right)$ of 1.4389 . The carbinol was prepared by the reaction between methylmagnesium bromide and 2,2,4-trimethyl-3-pentanone (see section IV-19).

In one experiment on the methylation of this chloride, 1.7 moles of the chloride in $320 \mathrm{ml}$ of benzene was added to 2.5 moles of dimethyl zinc, using the previously described technic. Distillation analysis of the product of reaction showed the presence of 0.4 mole $(23.5 \%)$ of 2-isopropyl-3,3dimethyl-1-butene, and 0.81 mole $(47.5 \%)$ of 2,3,3,4-tetramethyl-1-pentene, both formed by dehydrochlorination of the alkyl chloride. In addition, there was found 0.38 mole (assuming $\mathrm{C}_{10} \mathrm{H}_{22}$ ) of material that boiled $150^{\circ}$ to $160^{\circ} \mathrm{C}$, and from which no pure material could be isolated.

In another experiment 10.7 moles of 3 -chloro2,2,3,4-tetramethylpentane was treated with 11.0 moles of methylmagnesium bromide in ether solution. The reaction was allowed to take place over a period of 3 weeks at $15^{\circ}$ to $22^{\circ} \mathrm{C}$. The products of the reaction, was determined by distillation analysis, consisted of 3.0 moles $(28 \%)$ of 2-isopropyl-3,3-dimethyl-1-butene, and 5.7 moles $(53 \%)$ of 2,3,3,4-tetramethyl-1-pentene, formed by dehydrochlorination of the alkyl chloride. In addition, there was found 0.5 mole $(4.7 \%)$ of crude 2,2,3,3,4-pentamethylpentane. (Boiling range $=158^{\circ}$ to $167^{\circ} \mathrm{C}, n_{D}^{20}=1.4354$ to 1.4369 .)

It is interesting to note that in both of these trials, the dehydrochlorination of the alkyl chloride led to approximately the same relative proportions of the two nonenes, namely, 1 part of 2-isopropyl-3,3-dimethyl-1-butene and 2 parts of 2,3,3,4-tetramethyl-1-pentene. This proportion is not the same as occurs when the carbinol itself is dehydrated. In that case the proportions are 3 parts of 2-isopropyl-3,3-dimethyl-1-butene and 1 part of 2,3,3,4-tetramethyl-1-pentene [31,38].

(b) Pentamethylpentanes from 2,2,3,4,4-Pentamethyl-3pentanol (trial 1 )

In an attempt to prepare 2,2,3,4,4-pentamethylpentane, it has been found that 2,2,3,4,4-pentamethyl-3-pentanol will dehydrate under the influence of iodine to a mixture of two decenes, which, on hydrogenation, yields both of the pentamethylpentanes.

In 1933 Whitmore and Laughlin [38] reported the dehydration of 2,2,3,4,4-pentamethyl-3pentanol by means of $\beta$-naphthalene sulfonic acid to give 2-t-butyl-3,3-dimethyl-1-butene without appreciable rearrangement. They also reported a small amount of low-boiling, unidentified material.

As this reaction offered a means of preparing 2,2,3,4,4-pentamethylpentane, a trial run was made. When the carbinol was dehydrated with $\beta$-naphthalene sulfonic acid at atmospheric pressure, the products of the reaction consisted of isobutylene, 2,3-dimethyl-1-butene, 2,3-dimethyl2-butene, and only a small amount of higherboiling material. No 3,3-dimethyl-1-butene was found in the reaction products.

Dehydration of the carbinol with iodine was found to yield a mixture of decenes, comprising of 2-t-butyl-3,3-dimethyl-1-butene and 2,3,3,4,4pentamethyl-1-pentene.

(1) Preparation of 2,2,4-trimethyl-3-pentanone and 2,2,4,4-tetramethyl-3-pentanone.-2,2,4-Trimethyl-3-pentanone was prepared by the HallerBauer synthesis [17], in toluene solvent by the action of sodium amide and then methyl sulfate on 2,4-dimethyl-3-pentanone. Sodium amide was made in 90- to 94-percent yield by the method described in Organic Syntheses [29]. The crude 2,2,4-trimethyl-3-pentanone was methylated a second time by the same method to give 2,2,4,4tetramethyl-3-pentanone. The manipulative details of these reactions are described by Whitmore and Laughlin [38]. The over-all yield was 58 percent of that theoretically possible, calculated without including recovered 2,4-dimethyl-3-penta- 
none and 2,2,4-trimethyl-3-pentanone, which were recycled in the synthesis.

Part of the 2,2,4 trimethyl-3-pentanone used in this synthesis was prepared at Pennsylvania State College (F. C. Whitmore), the rest was synthesized at the Bureau as described. A charge of this ketone was fractionated in column 1 for the isolation of a pure sample for physical-constant measurements. In the same column, a sample of the 2,2,4,4-tetramethyl-3-pentanone was also distilled for the same purpose.

(2) Preparation of 2,2,3,4,4-pentamethyl-3-pentanol.-A solution of 10 moles of methylmagnesium bromide was reacted with 8.75 moles of $2,2,4,4-$ tetramethyl-3-pentanone and the product worked up in the usual manner. Fractionation of the product in column 4 at a pressure of $57 \mathrm{~mm} \mathrm{Hg}$ gave a forerun of $307 \mathrm{ml}$ of material that boiled below $105^{\circ} \mathrm{C}$. At this point the carbinol began to solidify in the condenser, and the pale-yellow material remaining in the pot was found to be quite pure carbinol (melting point above $37^{\circ} \mathrm{C}$ ). A portion was recrystallized from ether for use in the determination of physical properties. The yield amounted to 75 percent of the theoretical quantity.

(3) Dehydration of 2,2,3,4,4-pentamethyl-3-pentanol with $\beta$-naphthalene sulfonic acid.-Dehydration of $897 \mathrm{~g}$ (5.7 moles) of 2,2,3,4,4-penta methyl3-pentanol with $8 \mathrm{~g}$ of $\beta$-naphthalene sulfonic acid under a fractionating column resulted in the distillation of a water layer, an organic layer $(855 \mathrm{ml})$, and about $50 \mathrm{ml}$ of material collected in a dry-ice trap. The organic layer which smelled strongly of sulfur dioxide and hydrogen sulfide, was washed, dried, and distilled from sodium, and gave the following fractions:

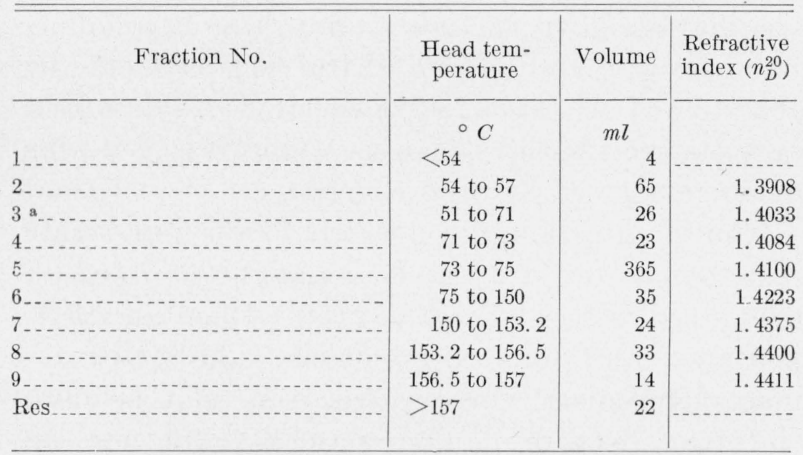

\footnotetext{
a Distillation interrupted.
}

A considerable quantity of gas was evolved during the distillation. This gas boiled at about $-4^{\circ} \mathrm{C}$, was readily absorbed in sulfuric acid, and absorbed bromine. Regeneration from sulfuric acid solution by neutralization resulted in $t$-butyl alcohol. This identifies the gas as isobutylene. The other principal products of the reaction were fraction 2 (2,3-dimethyl-1-butene), fraction 5 (2,3dimethyl-2-butene), and fractions 7 and 8 , which probably contained a mixture of 2,3,3,4,4-pentamethyl-1-pentene and 2-t-butyl-3,3-dimethyl-1butene. As the products of this distillation did not yield the desired compounds in any appreciable quantity, more elaborate analysis was not undertaken.

(4) Dehydration of 2,2,3,4,4-pentamethyl-3-pentanol with iodine.-A charge of 2,2,3,4,4-pentamethyl-3-pentanol (640g, 4.1 moles) was refluxed with $4 \mathrm{~g}$ of iodine, and the product was distilled through a short fractionating column, yielding 70 $\mathrm{ml}$ of water and $700 \mathrm{ml}$ of organic material. The organic layer was washed, dried, and fractionated roughly. The distillate from three runs were combined, yielding $1,950 \mathrm{ml}$ of material, which, on further fractionation, gave $1,800 \mathrm{ml}$ that boiled at $140^{\circ}$ to $155^{\circ} \mathrm{C}$. The residue was semisolid and had an odor similar to that of a carbinol. The $140^{\circ}$ to $155^{\circ} \mathrm{C}$ fraction was redistilled into the following fractions:

\begin{tabular}{|c|c|c|c|}
\hline Fraction No. & $\begin{array}{c}\text { Head } \\
\text { temperature }\end{array}$ & Volume & $\begin{array}{c}\text { Refractive } \\
\text { index } \\
\left(n_{D}^{20}\right) \\
\text { (uncorr.) }\end{array}$ \\
\hline . & ${ }^{\circ} C$ & $m l$ & \\
\hline $1 \ldots$ & 100 to 148.2 & 55 & 1. 4314 \\
\hline $2 \ldots \ldots$ & 148.2 to 149.0 & 43 & 1. 4348 \\
\hline 3 & 149.0 to 149.6 & 283 & 1. 4355 \\
\hline 4 & 149.6 to 151.0 & 460 & 1. 4355 \\
\hline 5 & 151.0 to 152.0 & 190 & 1. 4367 \\
\hline 6 & 152.0 to 153.0 & 55 & 1. 4381 \\
\hline 7 & 153.0 to 155.0 & 50 & 1.4396 \\
\hline 8 & 155.0 to 157.0 & 26 & 1. 4410 \\
\hline
\end{tabular}

A constant-boiling portion of fraction 3 was reserved for determination of physical constants and ozonolysis. At $157^{\circ} \mathrm{C}$, solid material started to form in the condenser, so the distillation was stopped. The cooled residue in the flask was solid, melting at $34.5^{\circ}$ to $37.5^{\circ} \mathrm{C}$, but a mixture of this compound and the original carbinol was liquid at room temperature. The material was soluble in ether, insoluble in water, slightly 
soluble in 85 percent phosphoric acid, and was unaffected by sodium.

Analysis showed the presence of 83.1 percent of carbon and 13.8 percent of hydrogen. ${ }^{5}$ Because of the volatility of the compound, these results may be low. By extending the $\mathrm{C}-\mathrm{H}$ content to total 100 percent, the analysis was calculated to be 85.8 percent of carbon and 14.2 percent of hydrogen, which agrees with the analysis of an alkene. The molecular weight was found cryoscopically to be 142.4 (theory for $\mathrm{C}_{10} \mathrm{H}_{20}=140.2$ ).

At this point the distillation of the solid olefin was continued after provision had been made to prevent solidification of material in the condenser. This distillation gave the following fractions:

\begin{tabular}{|c|c|c|}
\hline Fraction No. & $\begin{array}{c}\text { Head } \\
\text { temperature }\end{array}$ & Weight \\
\hline & $\left({ }^{\circ} \mathrm{C}\right)$ & $(g)$ \\
\hline $9 \ldots \ldots$ & 157.0 to 157.2 & 30.1 \\
\hline $10 \ldots$ & 157. 2 to 158.0 & 18.6 \\
\hline $11 \ldots$ & 158.0 to 158.2 & 18.4 \\
\hline $12 \ldots$ & 158.2 & 27.7 \\
\hline $13 \ldots \ldots$ & 158.2 to 158.9 & 28.1 \\
\hline 14 & 158. 9 to 159.0 & 28.3 \\
\hline 15 & 159.0 to 159.0 & 28. 2 \\
\hline Residue & - & 39.1 \\
\hline
\end{tabular}

Ozonolysis was performed on fraction 15 .

(5) Ozonolysis of alkenes.

(a) Lower-Bolling Alrene (2-t-Butyl-3,3Dimethyl-1-Butene). Ozonization of 0.21 mole of alkene in $300 \mathrm{ml}$ of isopentane at $-5^{\circ}$ to $-10^{\circ} \mathrm{C}$ was accomplished in $12 \mathrm{hr}$. Oxygen containing 7.5 percent of ozone was used at the rate of $7,500 \mathrm{ml} / \mathrm{hr}$. The solvent was not removed prior to decomposition because the ozonide proved to be a solid. Decomposition was effected by means of the technic developed by Whitmore and Church [34]. The reaction was of medium violence and gave rise to $36.5 \mathrm{ml}$ of oil and $150 \mathrm{ml}$ of water layer. Analysis of the water layer showed the presence of 0.18 mole of formaldehyde, and no other low molecular weight aldehyde or ketone. The oil was distilled to yield $24.3 \mathrm{ml}$ of 2,2,4,4-tetramethyl-3-pentanone (boiling point $150^{\circ}$ to $155^{\circ} \mathrm{C}$ ), which, when treated with methylmagnesium bromide, gave 2,2,3,4,4-pentamethyl3-pentanol, the identity of which was proved by a mixed melting point with a known sample.

(b) Higher-Boiling Alkene (2,3,3,4,4-PentaMETHYL-1-PENTENE). In the same manner as

${ }^{3}$ Thanks are due K. C. Fleischer, of this Bureau, for this microanalysis. described above, 0.11 mole of the higher-boiling alkene was ozonized in $300 \mathrm{ml}$ of isopentane at $-10^{\circ}$ to $-20^{\circ} \mathrm{C}$ to yield 0.071 mole of formaldehyde and $9 \mathrm{~g}$ of an oil (boiling point $172^{\circ} \mathrm{C}$, $\left.n_{D}^{24}=1.4149\right)$. This oil gave a positive iodoform test, and was oxidized by 50 percent nitric acid to 2,2,3,3-tetramethyl butanoic acid [22, 23]. After several crystallizations from alcohol, this acid melted at $196^{\circ}$ to $197^{\circ} \mathrm{C}$, the same value reported by Whitmore, Marker, and Plambeck, Jr. [41]. The neutral equivalent was found to be 147.3. The amide was prepared and found to melt at $201.5^{\circ}$ to $202^{\circ} \mathrm{C}$, which agrees with the melting point found by Whitmore, et al. [41] $\left(201^{\circ}\right.$ to $\left.202^{\circ} \mathrm{C}\right)$. The ketone gave a 2,4 -dinitrophenylhydrazone, which melted at $182^{\circ}$ to $183^{\circ} \mathrm{C}$. The ketone was therefore considered to be $3,3,4,4$ tetramethyl-2-pentanone.

(6) Hydrogenation of the decenes. The crude lower-boiling alkene from the dehydration of 2,2,3,4,4-pentamethyl-3-pentanol (fractions 2 to 8 , inclusive) was hydrogenated and filtered through silica gel. Distillation in column 5 gave:

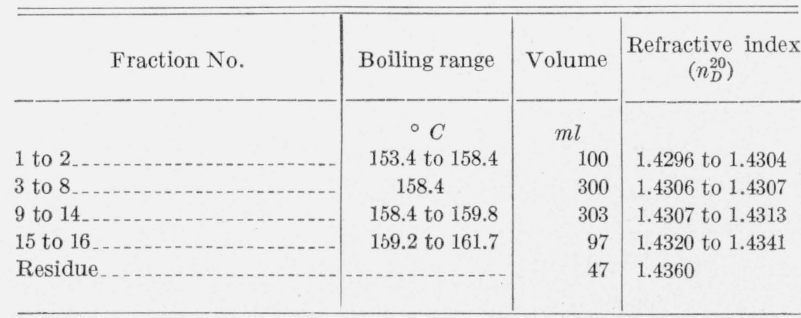

An analysis of the distillation curve showed the presence of $735 \mathrm{ml}$ of 2,2,3,4,4-pentamethylpentane, and $112 \mathrm{ml}$ of 2,2,3,3,4-pentamethylpentane.

Hydrogenation of the higher-boiling alkene was carried out in a solvent (2,2,4-trimethylpentane). Distillation gave, in addition to the solvent, a small forerun and $247 \mathrm{ml}$ of fractions collected at $163^{\circ}$ to $164^{\circ} \mathrm{C}\left(n_{D}^{20}=1.4358\right.$ to 1.4361$)$. The best samples of both decanes were reserved for measurement of physical constants.

The yield of alkanes isolated in the pure state (calculated on 2,2,4,4-tetramethyl-3-pentanone) amounted to 25.8 percent of 2,2,3,4,4-pentamethylpentane, and 11.4 percent of 2,2,3,3,4-pentamethylpentane. These yields could not be used to form a definite opinion of the reaction nor can much weight be placed on the ratio of products found, since a loss experienced in the distillation 
and handling of the higher-boiling decene is not accounted for.

(c) Pentamethylpentanes from 2,2,3,4,4-Pentamethyl-3pentanol (trial 2)

The second run of this series of reactions was made to increase the stock of hydrocarbons and to obtain more information on the ratio of products formed by dehydration of the carbinol.

(1) Preparation of 2,2,4-trimethyl-3-pentanon:- For this second synthesis, an easier method was devised for making 2,2,4-trimethyl-3-pentanone. This method was an adaptation of that described by Nef [26], who obtained this ketone by the exhaustive methylation of acetone, methylisopropyl ketone, diethyl ketone, or pinacolone with methyl iodide and potassium hydroxide in a sealed tube at $140^{\circ} \mathrm{C}$. The method used in the present work substituted the less expensive methyl bromide for methyl iodide in the methylation of commercial 2,4-dimethyl-3-pentanone.
Several runs of various sizes were made and the results are summarized in table 5. These reactions were carried out in hydrogenation bombs. The bomb was chilled by solid carbon dioxide and charged with the reactants, then sealed and heated to the temperature indicated. As the reaction is exothermic, it was found difficult to hold a predetermined narrow temperature range. (The operation could probably be made more efficient by pumping the methyl bromide into the reaction vessel as it is consumed by the reaction in order to obtain more stable reaction conditions.) When the reaction was complete the bomb was cooled and the contents washed well with water, dried, and fractionated. In one experiment (5-1) an attempt was made to distill the residue $(247 \mathrm{~g})$. It was found to contain lachrymatory materials, but little if any 2,2,4,4-tetramethyl-3-pentanone. (None of this compound was found by Nef in any of his methylation products.)

TABLE 5.-Meihylation of 2,4-Dimethyl-3-pentanone

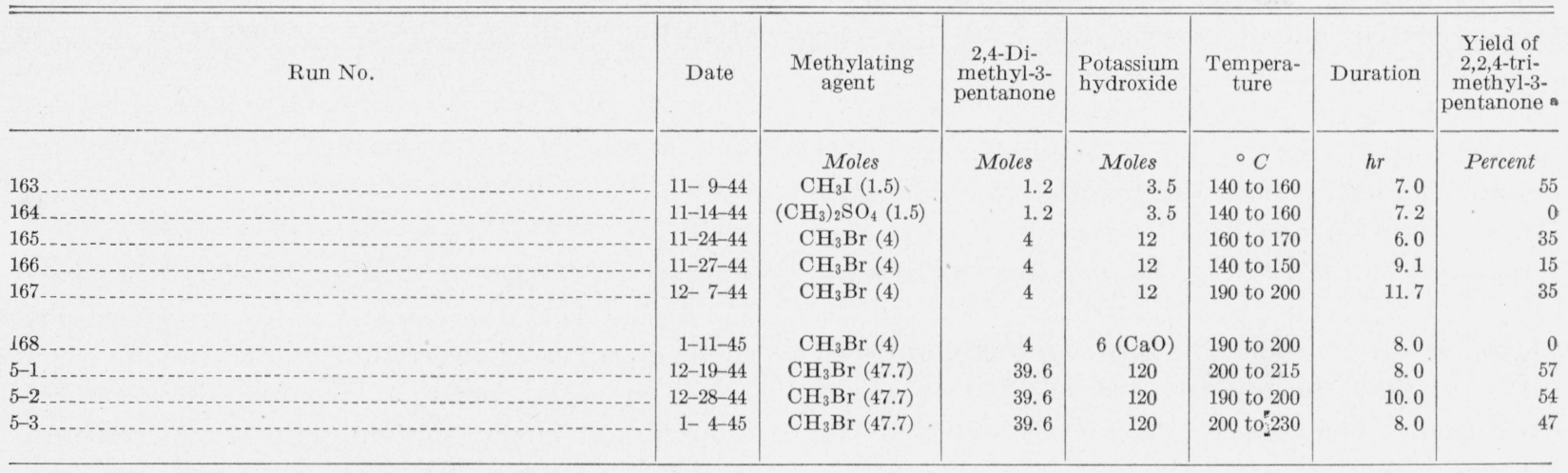

a Based on 2,4-dimethyl-3-pentanone consumed .

(2) Preparation of 2,2,4-4-tetramethyl-3-pentanone.-While the preparation of 2,2,4-trimethyl3 -pentanone was in progress, a new and simpler method for synthesizing 2,2,4,4-tetramethyl-3pentanone was described by Bartlett and Schneider [3]. This new procedure eliminated entirely the necessity of using sodium amide in the synthesis. The Bartlett and Schneider reaction involved interaction between $t$-butyl chloride, methyl trimethylacetate, and sodium sand to give a mixture of 2,2,4,4-tetramethyl-3-pentanone and 2,2,4,4-tetramethyl-3-pentanol as major products.

Several small-scale runs (1.6 to 2.0 moles) of this reaction were made. There was no appreciable difference in the yields of di-tertiary-butyl compounds from reactions in which technical "isooctane" (2,2,4-trimethylpentane) was used as a solvent and those in which isopentane was used. As the former solvent is considered safer, it was used in the majority of the trail runs and in the large-scale run. Slightly larger (2 to $5 \%$ ) yields were obtained when sodium sand was used rather than sodium wire. In none of the smallscale runs did the yield of combined di-tertiarybutyl compounds exceed 53 percent. (Bartlett and Schneider report yields up to $71 \%$ ). After the technic for handling this reaction had been sufficiently developed, a large run was made in the stainless-steel kettle.

(a) Methyl Trimethylacetate.-To a solution of $53 \mathrm{~kg}$ (177 moles) of sodium dichromate dihydrate (technical) in 98 liters of water in the 
glass-lined reactor was added 39.9 liters of concentrated sulfuric acid. The solution was heated to $82^{\circ} \mathrm{C}$ and $6.6 \mathrm{~kg}$ (59 moles) of 2,4,4-trimethyl-2pentene $(97 \%$ pure, see section IV-28) was added over a period of $5 \mathrm{hr}$. The rate of addition was regulated so that the temperature of the mixture did not exceed $88^{\circ} \mathrm{C}$. Then about 3 liters of methyl alcohol was added to use the excess dichromate, and the mixture was subjected to steam distillation. There was obtained thereby $5.76 \mathrm{~kg}$ of organic layer and about 30 liters of aqueous layer. The aqueous layer yielded, on distillation, an additional $0.82 \mathrm{~kg}$ of organic material. The crude product was distilled in columns 4 and 5 , and yielded $3.91 \mathrm{~kg}$ of trimethylacetic acid (bp $160^{\circ}$ to $\left.165^{\circ} \mathrm{C}\right)(65.0 \%$ yield).

The methyl ester of trimethylacetic acid was prepared in the usual manner by refluxing a solution of the acid in methyl alcohol. Sulfuric acid was used as the catalyst.

(b) 2,2,4,4-Tetramethyl-3-Pentanone.-Sodium sand, from $6.8 \mathrm{~kg}$ (300 moles) of sodium was prepared under toluene (22 liters) in the usual manner. The mixture was cooled to $15^{\circ} \mathrm{C}$ and 16 liters of technical "isooctane" (2,2,4-trimethylpentane) and $16 \mathrm{~kg}$ (173 moles) of $t$-butyl chloride added. After the reaction was initiated by the addition of a small quantity of ester, the remainder (total $7.98 \mathrm{~kg}, 68.5$ moles) was added during $4 \mathrm{hr}$, while the temperature was maintained at $35^{\circ}$ to $40^{\circ} \mathrm{C}$. Stirring was continued for $8 \mathrm{hr}$, then the mixture was allowed to stand overnight. The product was worked up in the manner described by Bartlett and Schneider. Distillation gave $2.57 \mathrm{~kg}$ (18.1 moles) of 2,2,4,4tetramethyl-3-pentanone (bp $151.5^{\circ}$ to $156.0^{\circ} \mathrm{C}$ ), $666 \mathrm{~g}$ of intermediate and $2.72 \mathrm{~kg}$ (18.9 moles) of 2,2,4,4-tetramethyl-3-pentanol (bp $167^{\circ}$ to $173^{\circ} \mathrm{C}$ ). Including the intermediate, this represents a yield of approximately 61 percent, based on methyl trimethylacetate.

The carbinol fraction and the intermediate containing carbinol were combined and oxidized in two batches. In each batch $1.36 \mathrm{~kg}(9.45$ moles) of carbinol and $333 \mathrm{~g}$ of intermediate ${ }^{6}$ were suspended in a solution of $1,255 \mathrm{~g}$ of sodium dichromate dihydrate in $1,170 \mathrm{ml}$ of water. While the reaction mixture was held at $45^{\circ}$ to

\footnotetext{
${ }_{6}^{6}$ The intermediate contained approximately 50 percent carbinol, and 50 percent ketone. The total quantity of carbinol oxidized in each batch was calculated to be 10.65 moles plus 1.2 moles of ketone in the intermediate.
}

$60^{\circ} \mathrm{C}$, a solution of $2,300 \mathrm{ml}$ concentrated sulfuric acid in $2,170 \mathrm{ml}$ of water was added during 2 days, after which the reaction mixture was stirred and heated to $50^{\circ} \mathrm{C}$ for 1 day. The organic material was then steam distilled, dried, and fractionated. There was thereby obtained $1.35 \mathrm{~kg}$ (9.52 moles) of ketone (bp $151^{\circ}$ to $\left.154^{\circ} \mathrm{C}\right)(78 \%$ yield).

In the same manner, all the 2,2,4,4-tetramethyl3-pentanol obtained in the several preliminary runs was oxidized to ketone, and all he ketone from the several sources, was combined. This included a small amount prepared by the HallerBauer reaction [17].

(c) Preparation and Dehydration of 2,2,3,4 4-Pentamethyl-3-Pentanol. - The pentamethyl. pentanol was prepared in the manner already described. From $6.96 \mathrm{~kg}$ (49.0 moles) of $2,2,-, 4-$ tetramethyl-3-pentanone there was obtained 4.84 $\mathrm{kg}$ (30.6 moles) of 2,2,3,4,4-pentamethyl-3-pentanol $(62.6 \%$ yield $)$.

Dehydration of the carbinol was caused by refluxing with iodine. In a trial run, $332 \mathrm{~g}$ (1.98 moles) of carbinol was boiled with $3.3 \mathrm{~g}$ of iodine. During $2 \mathrm{hr}, 93 \%$ of the theoretical quantity of water was eliminated and collected. The organic layer was washed with sodium thiosulfate solution and with water, dried, and a tilled in column 17. The charge was 246

The decene fractions (bp $145^{\circ}$ to $158.9^{\circ} \mathrm{C}$ ) weighe $216.6 \mathrm{~g}$ (1.54 moles, $78 \%$ ). Analysis of the distillation curve showed that these fractions consisted of equal parts of the two isomers, 3,3dimethyl-2-t-butyl-1-butene and 2,3,3,4,4-pentamethyl-1-pentene.

Treatment of the main portion of the carbinol for the preparation of the pentamethylpentanes followed the procedure already described.

\section{2,2,5,5- and 2,2,4,5-Tetramethylhexanes}

The synthesis of 2,2,5,5- and 2,2,4,5-tetramethylhexanes was accomplished by the following reactions: (a) Oxidation of 2,4,4-trimethyl-1pentene to 4,4-dimethyl-2-pentanone (methylneopentyl ketone), (b) oxidation of this ketone to $t$-butylacetic acid, (c) conversion of the acid to methyl-t-butylacetate, (d) reaction of the ester with $t$-butylmagnesium chloride to give $2,2,5,5$ tetramethyl-3-hexanol, (e) dehydration of the carbinol to a mixture of 2,2,5,5-tetramethyl-3hexene, 2,3,5,5-tetramethyl-2-hexene and 2,3,5,5tetramethyl-1-hexene, and (f) hyrdogenation of 
the first-named alkene to 2,2,5,5-tetramethylhexane and of the last two alkenes to $2,2,4,5-$ tetramethylhexane.

(a) The oxidation of 2,4,4-trimethyl-1-pentene was carried out essentially in the manner disclosed by Whitmore, Homeyer, and Trent [37]. Several runs were made on olefin of 95 percent or higher purity. (The isolation of this olefin is described later.) In a typical run, 101 moles of alkene was oxidized during 10 days with sodium dichromate by the slow addition of sulfuric acid. There was obtained 1,800 $\mathrm{g}$ of acidic material and 9,360 ml of neutral oil, which, on distillation in column 3, gave $2,154 \mathrm{ml}$ of forerun, $4,150 \mathrm{~g}$ (36.4 moles) 4,4 dimechyl-2-pentanone (bp $123^{\circ}$ to $126^{\circ} \mathrm{C}$ ) and $2,000 \mathrm{ml}$ of residue. This yield of ketone is equivalent to 36 percent of the theoretical amount. The acidic material was found to be a complex mixture containing only minor quantities of trimethylacetic and $t$-butylacetic acid and was not further investigated.

(b) The hypohalite oxidation of the methylneopentyl ketone to $t$-butylacetic acid was accomplished by a modification of the reaction disclosed by Whitmore, Homeyer, and Trent [37]. .red from bromine and sodium hydroxide), . hereas in the present work the less expensive, commercially available calcium hypochlorite was used. Several small preliminary runs were made to develop familiarity with the reaction before a large run was undertaken. Three large runs were made, one of which is described.

A solution of $14.0 \mathrm{~kg}$ of technical sodium hydroxide in 38 liters of water was prepared. This solution was cooled to $19^{\circ} \mathrm{C}$ and to it was added about $90 \mathrm{~kg}$ of cracked ice and $13 \mathrm{~kg}$ of commercial calcium hypochlorite ( $70 \%$ available chlorine). The temperature thereby obtained was about $-4^{\circ} \mathrm{C}$. The ketone (50 moles) was then added during $3 \mathrm{hr}$. The temperature of the reaction mixture remained below $+5^{\circ} \mathrm{C}$ during this addition. An additional $25 \mathrm{~kg}$ of cracked ice was added and the mixture stirred for $10 \mathrm{hr}$, after which it was heated to $65^{\circ}$ to $70^{\circ} \mathrm{C}$ for $5 \mathrm{hr}$. After cooling the mixture to $20^{\circ} \mathrm{C}, 19.7$ liters of sulfuric acid was added slowly and the products steam distilled. The crude product was distilled in several batches from a 1-liter claisen flask. There was thereby obtained $4,070 \mathrm{~g}$ (31.3 moles,
$63 \%$ ) of acid collected between $180^{\circ}$ and $190^{\circ} \mathrm{C}$. No further purification of the acid was made.

(c) The methyl ester of $t$-butylacetic acid was made in the usual manner. In a typical run a solution of $4,140 \mathrm{~g}$ ( 35.7 moles $)$ of acid and $300 \mathrm{ml}$ of concentrated sulfuric acid in 10 liters (250 moles) of methanol was heated to reflux for two periods of $7 \mathrm{hr}$ each. The crude product thereby obtained was distilled in column 5 and gave $3,560 \mathrm{~g}$ (27.4 moles, $76.7 \%$ ) of ester, which was collected at $125^{\circ}$ to $127^{\circ} \mathrm{C}$.

(d) The preparation of 2,2,5,5-tetramethyl-3hexanol was carried out by the use of the reaction described by Moersch [25], which is an adaptation of that used by Heyd [18].

To the Grignard reagent prepared from 326 gram atoms of magnesium and 326 moles of $t$-butyl chloride was added $6,815 \mathrm{~g}$ (52.4 moles) of methyl $t$-butylacetate during $8 \mathrm{hr}$. The reaction mixture was refluxed $7 \mathrm{hr}$ each day for 3 days and allowed to stand each night. Decomposition was caused by dilute sulfuric acia (17 kg of concentrated acid and $20 \mathrm{~kg}$ of water and ice). The product was steam distilled, and the aqueous layer extracted with ether. The organic layers were combined and the ether removed in column 11 . The residue was redistilled in columns 24 and 7 , yielding $6,507 \mathrm{~g}$ of carbinol collected at $166^{\circ}$ to $170^{\circ} \mathrm{C}$. This is equivalent to 41.2 moles, or 79 percent yield. Moersch reported 85 percent yield [25].

(e) Three preliminary experiments were made on the dehydration of 2,2,5,5-tetramethyl-3hexanol and on the rearrangement of the resulting olefins. In one run, $117 \mathrm{~g}$ ( 0.70 mole $)$ of carbinol was passed over $256 \mathrm{~g}(330 \mathrm{ml})$ of alumina (Baker Hydralo, lot 91942$)$ at $300^{\circ}$ to $305^{\circ} \mathrm{C}$ at the rate of $47 \mathrm{~g} / \mathrm{hr}$. The catalyst tube was $2.5 \mathrm{~cm}$ in diameter. The water recovered amounted to 10.8 $\mathrm{ml}(0.6$ mole, $86 \%)$. The product was dried and fractionated in column 17 . The yield of decenes amounted to 70 percent $(78 \%$ on basis of carbinol consumed), and consisted of 34.5 mole percent 2,2,5,5-tetramethyl-3-hexene, 35.2 percent $2,3,5,5$ tetramethyl-1-hexene, and 30.2 percent $2,3,5,5-$ tetramethyl-2-hexene.

In another experiment, $118 \mathrm{~g}$ of carbinol was dehydrated under the same conditions, except that the rate was $98 \mathrm{~g} / \mathrm{hr}$. In this case, a yield of 46 percent olefins $(73 \%$ on basis of carbinol consumed) was obtained. The mixture of olefins contained 34.8 percent 2,2,5,5-tetramethyl-3-hex- 
ene, 42.0 percent 2,3,5,5-tetramethyl-1-hexene, and 23.2 percent 2,3,5,5-tetramethyl-2-hexene.

To determine the extent of rearrangement of the olefins, a mixture of decenes was passed over the catalyst at $300^{\circ}$ to $310^{\circ} \mathrm{C}$ at the rate of 44 $\mathrm{g} / \mathrm{hr}$. Analysis of the resultant mixture showed that the original mixture was isomerized as follows: 2,2,5,5-tetramethyl-3-hexene, from 13.5 to 16.8 percent; $2,3,5,5$-tetramethyl-1-hexene, from 46.2 to 31.2 percent; and 2,3,5,5-tetramethyl-2hexene, from 40.0 to 52.0 percent.

The bulk of the carbinol was dehydrated in the manner used in the first experiment. The resultant mixture was dried and distilled in column 5 . The carbinol recovered was recycled for dehydration. In this way, $4,999 \mathrm{~g}$ of crude olefin mixture was obtained $(86.6 \%$ yield $)$. This mixture was separated roughly in column 5 into concentrates boiling at $121^{\circ}$ to $127^{\circ} \mathrm{C}, 139^{\circ}$ to $145^{\circ} \mathrm{C}$, and $152^{\circ}$ to $158^{\circ} \mathrm{C}$, and intermediate fractions. A sample $(500 \mathrm{ml})$ of each hydrocarbon was redistilled in column 17 for preparation of pure compounds. The impure fractions from each of these distillations were returned to the appropriate concentrate. These olefins have been identified previously [18, 25].

(f) Each of the olefin concentrates was hydrogenated separately, as was the combined intermediate. The latter two olefin concentrates gave the same paraffin and were combined for distillation. Purification of both paraffins was accomplished in column 18. The best 500-ml samples from each distillation were redistilled in column 17 , and physical constants were measured on the best samples from these distillations.

\section{2,2,3,3-Tetramethylhexanes}

This hydrocarbon was synthesized at Pennsylvania State College (Frank C. Whitmore) and purified at the Bureau. When received, the sample (2 gallons) contained chlorides, which were removed by boiling with alcoholic alkali. The product was washed, dried, and fractionated in columns 19 and 20. The best portion from one of these distillations was refractionated in column 17 . Physical constants were determined on the best fractions from this distillation.

\section{3,3,4,4-Tetramethylhexane}

The method of preparation of this decane is similar to that used in the preparation of $2,2,3,3$ - tetramethylpentane, and involved the reaction between ethylmagnesium chloride and 2-chloro2,3,3-trimethylpentane.

In the exploratory synthesis, 2,3,3-trimethyl1-pentene (boiling range $108.34^{\circ}$ to $108.40^{\circ} \mathrm{C}$, $n_{D}^{20}=1.4170$ to 1.4172 ) was converted to the chloride, 2-chloro-2,3,3-trimethylpentane, by reaction with dry hydrogen chloride at $-30^{\circ} \mathrm{C}$. The product was fractionated in column 4. The forerun of unchanged olefin was used in the preparation of more chloride. The chloride used in the coupling reaction was that collected between $81^{\circ}$ and $82^{\circ} \mathrm{C}$ at $57 \mathrm{~mm} \mathrm{Hg}$.

To the Grignard solution prepared from 10 gram atoms of magnesium and 10 moles of ethyl bromide, there was added, during 7 days, 9.3 moles $(1,382 \mathrm{~g})$ of the chloride. On the twelfth day the mixture was worked up. The ether was removed from the organic layer and the residue refluxed $6 \mathrm{hr}$ with alcoholic alkali $(10 \% \mathrm{KOH})$ to remove chlorides. The washed, dried, chloridefree material was distilled in column 17 .

A large run of the preparation of this hydrocarbon is in progress. From this run a considerably purer compound is expected.

\section{2,3-Dimethyl-1-butene and 2,3-Dimethyl-2-Butene}

The preparation and properties of 2,3-dimethyl2-butene, and 2,3-dimethyl-1-butene have been reported previously by this Bureau [7]. Although the 2,3-dimethyl-1-butene reported was relatively pure, the 2,3-dimethyl-2-butene was decidedly impure. The boiling range of the best sample of the latter was about $0.4^{\circ} \mathrm{C}$, even after repeated fractionation, whereas other hydrocarbons prepared and reported in the same paper had boiling ranges of less than $0.01^{\circ} \mathrm{C}$. The wide boiling range has been attributed to the presence of peroxides in the sample. This tendency to form peroxides is much more pronounced in the 2,3dimethyl-2-butene than in the 1-isomer. As both alkenes result from the same reaction, the study of both compounds was repeated.

The method of preparing the alkenes was by dehydration of 2,3-dimethyl-2-butanol, by means of iodine. The carbinol was prepared by action of methylmagnesium bromide on methyl isobutyrate.

Several batches of methyl isobutyrate were made, in each of which 90 moles of methanol 
and 30 moles of isobutyric acid were refluxed for 6 to $8 \mathrm{hr}$ with $15 \mathrm{ml}$ of concentrated sulfuric acid. The product was recovered by adding water, extracting the unchanged acid by sodium carbonate solution, and saturating the aqueous layer with salt to recover unused alcohol and dissolved ester. The combined, nonacidic organic layer was distilled in columns $3,4,5$, and 6 . Only constantboiling $\left( \pm 0.1^{\circ} \mathrm{C}\right)$ material was reserved for subsequent steps. The yield amounted to 71 percent of the theoretical, based on original isobutyric acid.

In a typical run of the preparation of 2,3dimethyl-2-butanol 42 moles of methyl isobutyrate was added to 90 moles of methylmagnesium bromide in $12 \mathrm{hr}$. After the reaction mixture had been allowed to stand for $15 \mathrm{hr}$, it was warmed for $4 \mathrm{hr}$ and then treated with ice and dilute hydrochloric acid. The organic material was dried and distilled in column 6. After ether and unchanged ester had been removed, the carbinol was distilled at $76.4^{\circ}$ to $76.6^{\circ} \mathrm{C}$ at $152 \mathrm{~mm} \mathrm{Hg}$. The yield was $3,120 \mathrm{~g}$ ( $73 \%$, based on ester).

The dehydration of 2,3-dimethyl-2-butanol was accomplished by heating it with $1 \mathrm{gm}$ of iodine per liter of carbinol. The olefinic material thereby obtained was roughly separated in column 4 and consisted of approximately 3 parts of 2,3-dimethyl-2-butene and 1 part of 2,3-dimethyl-1butene. The residue from this distillation consisted of unchanged carbinol that had steam distilled during the dehydration step. This carbinol was returned to the dehydration process as it accumulated. In this way, a practically quantitative yield of alkenes was obtained.

Two charges of crude 2,3-dimethyl-2-butene were fractionated in column 1. The "middle cuts" from these distillations, the fractions of which had a constant refractive index $( \pm 0.00005)$, were combined and amounted to 3.6 liters of material. The 2,3-dimethyl-1-butene was fractionated in like manner, and 3.5 liters of material was obtained. The two hydrocarbons were then subjected to distillation in column 5 under conditions designed to destroy any peroxides present and to prevent their formation in the distillate. This was accomplished by adding hydroquinone to the distillation charge and by keeping the column, take-off, and delivery systems flushed with nitrogen. In this way, thirty-three 100-m] fractions of each hydrocarbon were obtained.
For measuring the physical properties of these olefins the same apparatus and methods previously described were used, but care was exercised to displace air in the apparatus with nitrogen during the determinations. Refractive indices were measured in the usual manner. Peroxide numbers (moles of active oxygen in 1,000 liters of solution) were determined by the method of Yule and Wilson [43].

For 2,3-dimethyl-1-butene, fraction 17 was used for determination of refractive index and density. The peroxide number of this fraction was 0.03 . Measurements of boiling points of this olefin were made with fractions 16 and 19 . The distillate from these determinations contained an unmeasurably small amount of peroxide. The freezing point of 2,3-dimethyl-2-butene was made on fraction 17 (0.07 peroxide number). Refractive-index and density measurements were made on fraction 21 (0.03 peroxide number) and boiling-point measurements on fractions 18,19 , and $20(0.04$ to 0.06 peroxide number). The measured values of the properties are given in table 6 .

Considerable difference of opinion exists regarding the freezing point of 2,3-dimethyl-1-butene. Schurman and Boord [30] report a "melting" point of $-120^{\circ}$ to $-123^{\circ} \mathrm{C}$ on material having a boiling range of $0.4^{\circ} \mathrm{C}$. Brooks, Howard, and Crafton [7] report a freezing point of $-140.1^{\circ} \mathrm{C}$ on a sample of high purity, which, however, undoubtedly contained some peroxide. Kistiakowsky and coworkers [20], using a sample having a boiling range of $0.01^{\circ} \mathrm{C}$ for determining the heat of hydrogenation, reported that the material congealed to a glass at low temperatures. Two attempts were made in this work to freeze samples that were peroxide free, but both were unsuccessful. An attempt to freeze samples recovered from the boiling-point distillates, which had been exposed to air for 2 weeks, also failed. Attempts were made to freeze samples containing small amounts of 2,2,4-trimethylpentane; those samples containing 0.58 and 2.4 mole percent of this impurity failed to freeze. One sample containing 1.43 mole percent of 2,2,4-trimethylpentane gave an indefinite freezing point at $-145.4^{\circ} \mathrm{C}$. This value seems to substantiate the previous [7] value of $-140.1^{\circ} \mathrm{C}$, and would indicate a very low heat of fusion, which may be a controlling factor in the determination of the freezing point. 
TABLE 6.-Physical properties of compounds prepared

$\mathrm{nf}=$ Material became very viscous or glassy without freezing to a crystalline solid.

$\mathrm{nd}=$ Material considered too impure to warrant determination of freezing point.

$\mathrm{mp}=$ Melting point .

$\mathrm{LBI}=$ Lower-boiling geometric isomer.

$\mathrm{HBI}=$ Higher-boiling geometric isomer

$\mathrm{CT}=$ Mixture of geometric isomers.

\begin{tabular}{|c|c|c|c|c|c|c|c|c|c|c|c|}
\hline \multirow{2}{*}{ Compound } & \multirow{2}{*}{$\begin{array}{l}\text { Freezing } \\
\text { point in } \\
\quad \text { air }\end{array}$} & \multirow{2}{*}{$\begin{array}{c}\text { Boiling } \\
\text { point at } \\
760 \mathrm{~mm} \mathrm{Hg}\end{array}$} & \multirow{2}{*}{$\begin{array}{l}d t B / d P \\
\text { at } 760 \\
m m ~ H g\end{array}$} & \multirow{2}{*}{$\begin{array}{c}\Delta \mathrm{T} \\
20 \text { to } 80 \\
\text { percent }\end{array}$} & \multicolumn{2}{|c|}{ Density at- } & \multirow{2}{*}{$\begin{array}{l}d D / d t \\
20^{\circ} \text { to } \\
25^{\circ} \mathrm{C}\end{array}$} & \multicolumn{2}{|c|}{$\begin{array}{l}\text { Refractive } \\
\text { index at- }\end{array}$} & \multirow{2}{*}{$\begin{array}{l}d n / d t \\
20^{\circ} \text { to } \\
25^{\circ} \mathrm{C}\end{array}$} & \multirow{2}{*}{$\begin{array}{l}\text { Date first } \\
\text { preparation } \\
\text { completed }\end{array}$} \\
\hline & & & & & $20^{\circ} \mathrm{C}$ & $25^{\circ} \mathrm{C}$ & & $20^{\circ} \mathrm{C}$ & $25^{\circ} \mathrm{C}$ & & \\
\hline$n$-Pentane $\ldots$ & $\begin{array}{r}{ }^{\circ} C \\
-129.75\end{array}$ & $\begin{array}{l}{ }^{\circ} \mathrm{C} \\
36.075\end{array}$ & $\begin{array}{l}{ }^{\circ} \mathrm{C} / m m \\
\mathrm{Hg} \\
0.0388\end{array}$ & $\begin{array}{c}{ }^{\circ} \mathrm{C} \\
0.006\end{array}$ & $\begin{array}{c}g / m l \\
0.62619\end{array}$ & $\begin{array}{c}g / m l \\
0.62133\end{array}$ & $\begin{array}{l}(g / m l) /{ }^{\circ} C \\
-0.00097\end{array}$ & $\begin{array}{c}n_{d} \\
\text { 1. } 35746\end{array}$ & $\begin{array}{c}n_{d} \\
\text { 1. } 35480\end{array}$ & $\begin{aligned} & n_{d} /{ }^{\circ} C \\
&-0.00053\end{aligned}$ & January 1941. \\
\hline 2-Methylbutane ........ & -159.9 & 27.853 & .0386 & .006 & .61963 & .61455 & -.00102 & 1. 35357 & 1. 35067 & -.06058 & December 1939. \\
\hline 2, 2-Dimethylpropane $\ldots \ldots$ & -16.60 & 9.503 & c. 0361 & .017 & -....... & -........ & - nes. & - & - & . & April 1942. \\
\hline 2-Methylpentane & -153.73 & 60. 266 & .0418 & .002 & .65285 & .64848 & -.00088 & 1. 37141 & 1.36866 & -.00055 & January 1944. \\
\hline 3-Methylpentane & nf & 63.265 & .0426 & .005 & .66438 & .65972 & -.00093 & 1. 37646 & 1. 37376 & -.00054 & November 1940. \\
\hline 2, 2-Dimethylbutane ... & $a-100.06$ & 49. 733 & a. 0407 & .004 & .64923 & .64422 & -.00100 & 1. 36873 & 1.36585 & -.00058 & May 1941. \\
\hline 2,3-Dimethylpentane & $\mathrm{nf}$ & 89.787 & .0450 & .002 & .69510 & .69090 & -.00084 & 1. 39193 & 1. 38950 & -.00049 & August 1941. \\
\hline 2, 4-Dimethylpentane & -119.86 & 80.508 & .0431 & .003 & .67315 & .66879 & -.00087 & 1. 38165 & 1.37903 & -.00053 & May 1941 \\
\hline 2-Methyl-3-ethylpentane ......... & $-114.94(\mathrm{mp})$ & 115.653 & .0477 & .004 & .71931 & .71523 & -.00082 & 1. 40403 & 1. 40173 & -.00046 & January 1941. \\
\hline 2, 2, 3-Trimethylpentane & b 112.32 & 109.847 & .0487 & .002 & .71608 & .71201 & -.00081 & 1. 40280 & 1. 40052 & -.00046 & August 1941. \\
\hline 2, 3,3-Trimethylpentane & -101.6 & 114. 767 & .0491 & .004 & .72621 & .72229 & -.00079 & 1. 40757 & 1. 40521 & -.00047 & October 1940. \\
\hline $2,2,4$-Trimethylhexane $\ldots \ldots \ldots$ & $-123.4(\mathrm{mp})$ & 126.54 & .0503 & .011 & .71555 & .71178 & -.00076 & 1. 40328 & 1. 40095 & -.00047 & October 1942. \\
\hline $2,2,5$-Trimethylhexane & $-105.89(\mathrm{mp})$ & 124.092 & .0485 & .005 & .70711 & .70313 & -0.0080 & 1. 39956 & 1. 39724 & -.00047 & July 1941. \\
\hline $2,3,5$-Trimethylhexane $\ldots . . . .$. & -127.9 & 131.37 & .0492 & .021 & .72191 & .71792 & -.00080 & 1. 40601 & 1. 40365 & -.00047 & June 1941. \\
\hline 2, 2-Dimethyl-3-ethylpentane & -99.30 & 133.834 & .0506 & .002 & .73478 & .73100 & -.00076 & 1. 41227 & 1. 41014 & -.00043 & September 1941. \\
\hline 2, 4-Dimethyl-3-ethylpentane & -122.4 & 136. 717 & .0504 & .009 & .73793 & .73415 & -.00076 & 1. 41371 & 1. 41146 & -.00045 & November 1940. \\
\hline $2,2,3,3$-Tetramethylpentane... & -10.04 & 140. 264 & .0512 & .009 & .75676 & .75300 & -.00075 & d 1.42365 & d 1.42146 & -.00044 & December 1940 . \\
\hline $2,2,3,4$-Tetramethylpentane $\ldots$ & -122.2 & 133.010 & .0501 & .007 & .73915 & .73537 & -.00076 & 1. 41462 & 1. 41242 & -.00044 & July 1941. \\
\hline $2,3,3,4$-Tetramethylpentane & -102.14 & 141. 544 & .0514 & .002 & .75489 & .75112 & -.00075 & 1. 42222 & 1. 42005 & -.00043 & November 1941. \\
\hline $2,2,3,3$-Tetramethylhexane.... & -54.03 & 160.310 & .0538 & .005 & .76450 & .76080 & -.00074 & 1. 42812 & 1. 42606 & -.00041 & November 1945 . \\
\hline $2,2,4,5$-Tetramethylhexane.... & $\mathrm{nf}$ & 147.875 & .0512 & .011 & .73542 & .73165 & -.00075 & 1. 41321 & 1. 41093 & -.00046 & October 1945 . \\
\hline $2,2,5,5$-Tetramethylhexane & -12.64 & 137.457 & .0500 & .004 & .71875 & .71480 & -.00079 & 1. 40550 & 1. 40315 & -.00047 & August 1945. \\
\hline $3,3,4,4$-Tetramethylhexane.... & nd & 170.0 & .046 & .57 & .7824 & .7789 & -.0007 & 1. 4368 & 1. 4346 & -.0004 & Do. \\
\hline $\begin{array}{l}\text { 2, 4-Dimethyl-3-isopropylpen- } \\
\text { tane. }\end{array}$ & -81.75 & 157.042 & .0544 & .012 & .75826 & .75460 & -.00073 & 1. 42465 & 1. 42246 & -.00044 & March 1945. \\
\hline $2,2,3,3,4$-Pentamethylpentane. & -36.49 & 166.05 & .0552 & .039 & .78009 & .77675 & -.00067 & 1. 43606 & 1. 43412 & -.00039 & February 1942. \\
\hline $2,2,3,4,4$-Pentamethylpentane_ & -38.81 & 159.29 & .0537 & .052 & .76702 & .76362 & -.00068 & 1. 43069 & 1. 42868 & -.00040 & October 1944. \\
\hline 3-Methyl-2-pentene (LBI) _..... & -135.4 & 67.8 & .039 & .16 & .6942 & .6898 & -.00088 & 1. 4016 & 1. 3989 & -.00054 & September 1942. \\
\hline 3-Methyl-2-pentene (HBI) ....... & -138.5 & 70.5 & .037 & .17 & .6986 & .6942 & -.00088 & 1. 4045 & 1. 4018 & -.00054 & Do. \\
\hline 2, 3-Dimethyl-1-butene......... & $\mathrm{nf}$ & 55.641 & .0429 & .002 & .67792 & .67312 & -.00096 & 1. 39044 & 1. 38745 & -.00060 & February 1944. \\
\hline 2, 3-Dimethyl-2-butene ........ & -74.30 & 73.206 & .0424 & .006 & .70795 & .70336 & -.00092 & 1. 41221 & 1. 40944 & -.00055 & October 1943. \\
\hline 2, 3, 3-Trimethyl-1-pentene .... & $\mathrm{nf}$ & 108.4 & .05 & .27 & .7352 & .7308 & -.00088 & 1.4174 & 1. 4151 & -.00047 & April 1945. \\
\hline $2,4,4$-Trimethyl-1-pentene $\ldots .$. & -93.56 & 101.437 & .0459 & .003 & .71500 & .71076 & -.00085 & 1. 40856 & 1. 40601 & -.00051 & June 1943. \\
\hline 2, 3, 4-Trimethyl-2-pentene .... & -113.38 & 116. 26 & .0493 & .082 & .74342 & .73914 & -.00086 & 1. 42736 & 1. 42500 & -.00047 & July 1942. \\
\hline $2,4,4$-Trimethyl-2-pentene $\ldots$. & -106.51 & 104. 914 & .0470 & .007 & .72124 & .71700 & -.00085 & 1. 41602 & 1.41350 & -.00050 & July 1943 \\
\hline 3, 4, 4-Trimethyl-2-pentene (CT)- & $\mathrm{nf}$ & 112.3 & .05 & .42 & .7392 & .7350 & -.00083 & 1. 4235 & 1. 4210 & -.00050 & July 1942. \\
\hline $2,3,5$-Trimethyl-2-hexene $\ldots$ & . & $\begin{array}{r}73(100 \mathrm{~mm}) \\
58 \quad(50 \mathrm{~mm})\end{array}$ & & & & & & 1. 4299 & & & October 1940. \\
\hline $\begin{array}{l}2,3,3,4 \text {-Tetramethyl-1-pen- } \\
\text { tene. }\end{array}$ & & 133.2 & .051 & .30 & .7587 & .7549 & -.00076 & 1. 4306 & 1.4283 & -.00046 & November 1941. \\
\hline $\begin{array}{l}\text { 4-Methyl-3-isopropyl-2-pen- } \\
\text { tene. }\end{array}$ & nf & $\begin{array}{c}138.0 \\
96(200 \mathrm{~mm})\end{array}$ & .046 & .88 & .7627 & .7591 & -.00072 & 1. 4353 & 1. 4328 & -.00049 & August 1940. \\
\hline $\begin{array}{l}\text { 2, 4-Dimethyl-3-ethyl-2-pen- } \\
\text { tene. }\end{array}$ & -83.5 & $\begin{array}{c}129.97 \\
88(200 \mathrm{~mm})\end{array}$ & .0459 & .073 & .74392 & .73997 & -.00079 & 1. 42346 & 1. 42112 & -.00047 & Do. \\
\hline $\begin{array}{l}\text { 4, 4-Dimethyl-3-ethyl-2-pen- } \\
\text { tene (CT). }\end{array}$ & $\mathrm{nf}$ & $\begin{array}{c}134.03 \\
84(150 \mathrm{~mm})\end{array}$ & .0466 & .060 & .7561 & .7521 & -.00079 & 1. 4309 & 1.4285 & -.00049 & August 1941. \\
\hline
\end{tabular}

a See reference [7].

b See reference [6].

- Calculated from data given in reference [2].

$\mathrm{d}$ The refractive indices of 2, 2, 3, 3-tetramethylpentane were determined by Leroy Tilton, of the Optical Instruments Section of this Bureau. 
TABLE 6.-Physical properties of compounds prepared-Continued

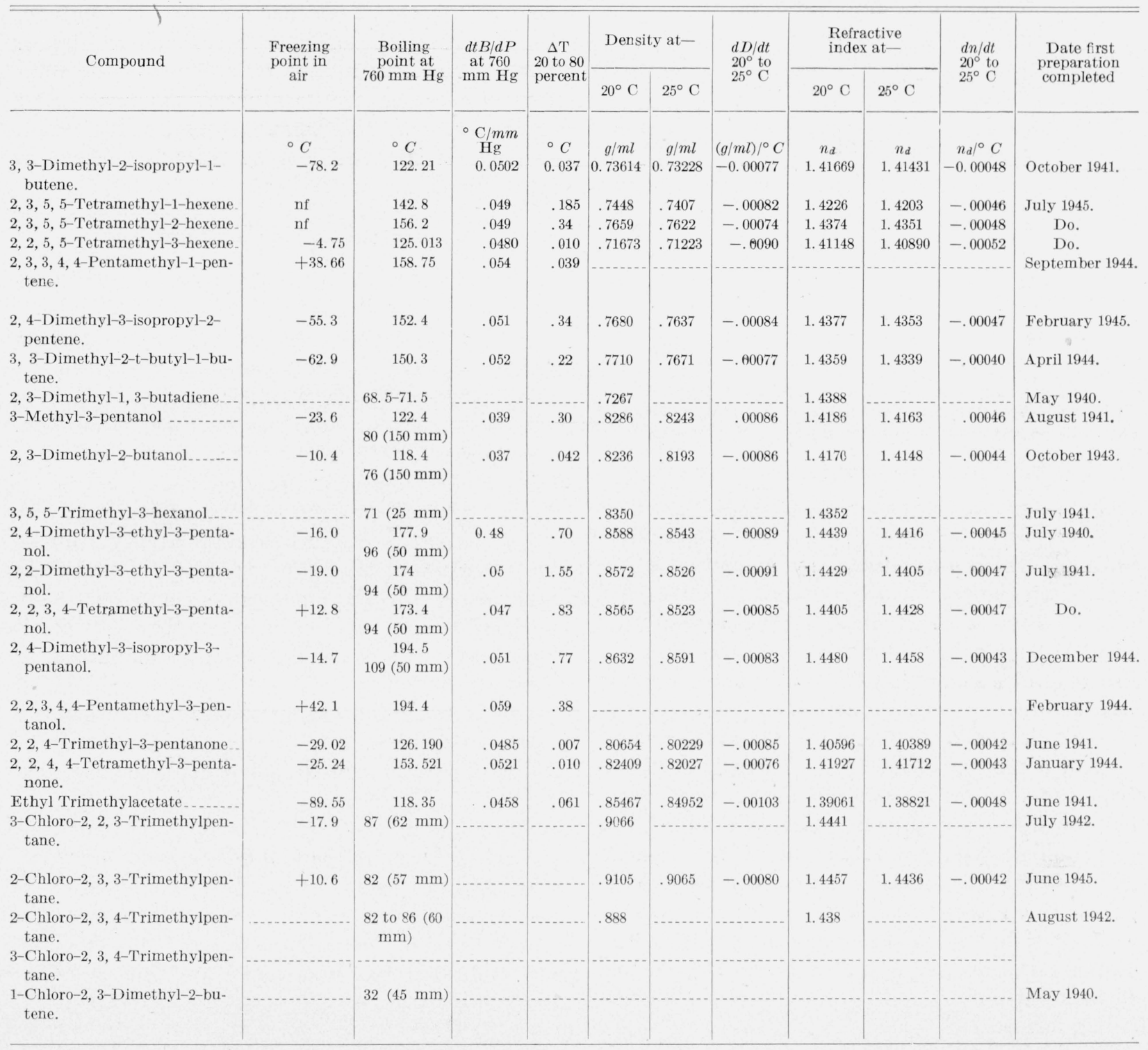

The presence of peroxides caused a marked change in the boiling ranges of these olefins. When samples of pure 2,3-dimethyl-1-butene were distilled in the boiling-point apparatus, the observed temperature changes (from 20 to $80 \%$ distilled) were less than $0.004^{\circ} \mathrm{C}$. The same material, after exposure to air for 2 months showed a distillation range $\left(20\right.$ to $80 \%$ ) of $0.11^{\circ} \mathrm{C}$. Still more pronounced is the effect of peroxides on 2,3-dimethyl-2-butene. Samples containing a small quantity of peroxide (peroxide number
0.04 ) distilled over a range of $0.007^{\circ} \mathrm{C}$ or less, but after this material had accumulated peroxides for 10 days, the distillation range was found to be $1.03^{\circ} \mathrm{C}$.

In order to determine the rate of peroxide formation under normal laboratory conditions, samples of purified alkenes were allowed to stand at room temperature in contact with air. Periodically, portions were withdrawn and analyzed for peroxides. The results of these analyses are given in table 7 . 
TABLE 7.-Rate of peroxide formation in 2,3-dimethyl-1butene and 2,3-dimethyl-2-butene

\begin{tabular}{|c|c|c|}
\hline \multirow{2}{*}{ Time } & \multicolumn{2}{|c|}{$\begin{array}{l}\text { Peroxide number (moles of ac- } \\
\text { tive oxygen per } 1,000 \text { liters of } \\
\text { solution)a }\end{array}$} \\
\hline & $\begin{array}{l}\text { 2,3-Dimethyl- } \\
\text { 1-butene }\end{array}$ & $\begin{array}{l}\text { 2,3-Dimethyl- } \\
\text { 2-butene }\end{array}$ \\
\hline Hours & & \\
\hline $0 \ldots$ & 0.10 & 0.30 \\
\hline 2.5 & .13 & 6.8 \\
\hline $5.0_{-}$ & .18 & 11.6 \\
\hline $10.0 \ldots$ & .26 & 19.0 \\
\hline 15 & .35 & 24.8 \\
\hline $20 \ldots \ldots \ldots$ & .44 & 29.9 \\
\hline $30 \ldots$ & .65 & 39.7 \\
\hline 40 & .86 & .... \\
\hline 50 & 1. 09 & - non \\
\hline
\end{tabular}

a For these hydrocarbons, at ordinary temperature, a peroxide number of 1 corresponds to approximately 0.012 mole percent peroxide impurity.

\section{3-Methyl-2-pentene (cis and trans)}

The two geometric isomers of 3-methyl-2-pentene were prepared by dehydration of 3-methyl-3pentanol, which was formed by action of ethylmagnesium chloride on 2-butanone.

To 53.8 moles of ethylmagnesium chloride was added 55.8 moles of 2-butanone in 5 liters of ether. The rield of carbinol (bp $75^{\circ}$ to $80^{\circ} \mathrm{C}$ at $142 \mathrm{~mm}$ $\mathrm{Hg}$ ) was 40 percent of the theoretical. The carbinol was dehydrated with $\beta$-naphthalene sulfonic acid to yield a mixture of olefins. A charge of 2,240 $\mathrm{ml}$ of the washed, dried olefin mixture was fractionated in column 2, which gave $240 \mathrm{ml}$ of the lower-boiling (cis?) and $960 \mathrm{ml}$ of the higherboiling (trans?) isomers. Physical constants were measured on the best samples of each isomer. Analysis of the distillation curve showed that the original mixture contained 26 percent (by volume) of the lower-boiling and 74 percent of the higherboiling forms.

The identification of these two olefins as cis and trans 3-methyl-2-pentene, rather than the isomers 3-methyl-2-pentene and 2-ethyl-1-butene, is based primarily on mass spectrometer studies. The two patterns formed by analysis of the compounds obtained are very nearly identical. ${ }^{7}$ No third component was isolated from the distillation, although it is probable that one was present in small quantity.

\section{Investigation of "Diisobutylene"}

It was necessary to isolate large quantities of the two diisobutylenes, 2,4,4-trimethyl-1-pentene, and 2,4,4-trimethyl-2-pentene, in order to provide samples for engine studies and for the syntheses of 4,4-dimethyl-2-pentanone and trimethylacetic acid by oxidation. For this purpose, a considerable quantity (450 liters) of the commercial mixture was systematically fractionated.

The original material was separated into five "cuts", or concentrates, by fractionation in column 11. Because of limited pot capacity, it was necessary to perform this operation in batches. Corresponding cuts from each batch were combined. The data on these distillations are summarized in table 8.

Cut $A$ (forerun) was an azeotrope containing a small quantity of 2,4,4-trimethyl-1-pentene with butyl alcohol and other polar compounds. This cut was not extensively investigated.

Cut $C$ (58 liters), the intermediate between cuts $B$ and $D$, was refractionated in column 11 to yield 34 liters of 2,4,4-trimethyl-1-pentene, which was combined with cut $B ; 14$ liters of intermediate, which was not further investigated; and 9 liters of residue, which was added to cut $D$. The

\footnotetext{
${ }^{7}$ For this opinion and for the experimental work from which it is drawn thanks are due Leo A. Wall, of the mass spectrometer laboratory of this Bureau.
}

TABLe 8.-Division of "diisobutylene" by preliminary fractionation

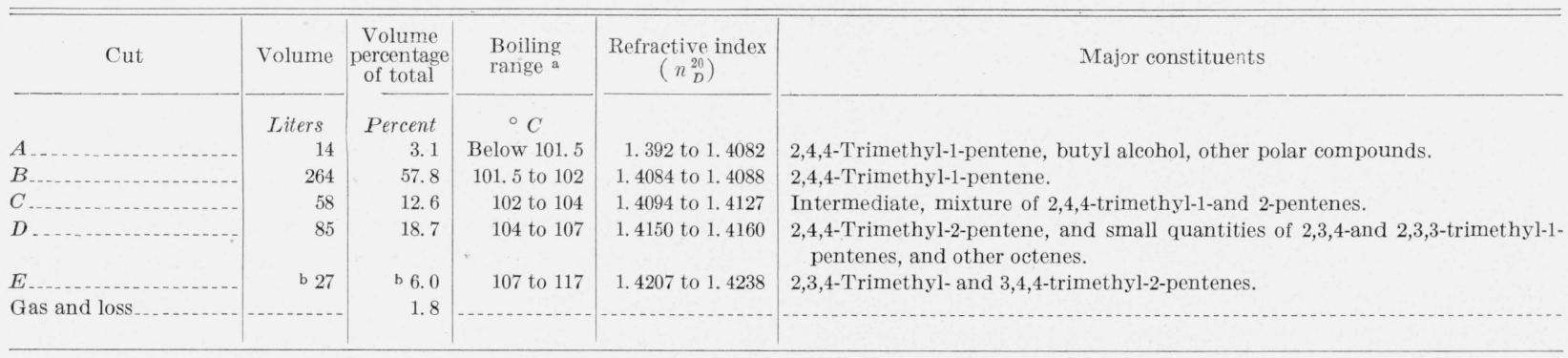

a Cottrell boiling-point measurements on first and last fractions.

b Includes residue. 
augmented cuts $B$ and $D$ were then designated as $B-1$, and $D-1$, respectively.

Cut $B-1$ (298 liters) was found to be about 96.7 percent pure 2,4,4-trimethyl-1-pentene; its freezing point was $-96.5^{\circ} \mathrm{C}$. A 170 -liter portion from the middle of this cut was refractionated in three runs, and 72 liters of purified 2,4,4-trimethyl-1-pentene was obtained, comprising fractions whose freezing points were in the range $-93.59^{\circ}$ to $-93.55^{\circ} \mathrm{C}$. Physical constants were measured on one of the fractions of $-93.55^{\circ} \mathrm{C}$ material. Those constants agree with those reported by Tongberg, Pickens, Fenske, and Whitmore [32]. This compound has been identified by ozonolysis by Whitmore and Church [34].

Cut $D-1$ (95 liters), a concentrate of 2,4,4trimethyl-2-pentene, was refractionated (in 2 runs). From these distillations, there was obtained 49.3 liters of high-purity 2,4,4-trimethyl-2pentene, composed of fractions whose freezing points were $-106.62^{\circ}$ to $-106.58^{\circ} \mathrm{C}$. A portion was refractionated in column 1 for isolation of a sample for physical-constants measurements. This compound was also characterized by Tongberg, et al. [32], and identified by Whitmore and Church [34].

The residue from distillation of cut $D-1$ was fractionated in column 1. From this distillation there was obtained two concentrates, designated $D-2$ and $D-3$.

Cut $D-2\left(745 \mathrm{ml}\right.$, bp $106.8^{\circ} \mathrm{C}, n_{D}^{20}=1.4149$ to $\left.1.4152, d^{20}=0.7265\right)$ was probably an impure sample of 2,3,4-trimethyl-1-pentene. Kuykendall [21] obtained the following properties for this compound: bp $106.7^{\circ}$ to $107.7^{\circ} \mathrm{C}, n_{D}^{20}=1.4146$ $d^{20}=0.726$.

Cut $D-3\left(804 \mathrm{ml}\right.$, bp $108.0^{\circ} \mathrm{C}, n_{D}^{20}=1.4162$ to $\left.1.4171, d^{20}=0.733\right)$ was a complex mixture in which 2,3,3-trimethyl-1-pentene was the probable major component. This partial identification is made by a comparison of the physical properties of cut $D$-3 with those of the 2,3,3-trimethyl-1pentene isolated from Shell "hot-acid polymer." (See next section.) As only small quantities of these cuts $(D-2$ and $D-3)$ were available, no extensive investigation was made on them.

Cut $E$ was combined with the residue from the preliminary fractionations. The combined mate- rial (27 liters) was fractionated in column 11, and yielded 3.8 liters of 3,4,4-trimethyl-2-pentene (cis and trans, presumably) (bp $112.0^{\circ}$ to $112.6^{\circ} \mathrm{C}$, $\left.n_{D}^{20}=1.4235, \quad d^{20}=0.739\right)$ and 4.5 liters of $2,3,4$ trimethyl-2-pentene (bp $116.1^{\circ}$ to $116.2^{\circ} \mathrm{C}$, $\left.n_{D}^{20}=1.4275, d^{20}=0.7428\right)$. These two compounds were identified by comparison of their physical properties with those of pure 3,4,4-trimethyl-2pentene and 2,3,4-trimethyl-2-pentene. The pure compounds were obtained by the distillation analysis of Shell "hot acid polymer", described in the next section, and by synthesis as described in section IV-20. Part of this sample of 3,4,4-trimethyl-2-pentene was oxidized to pinacolone. The entire sample of 2,3,4-trimethyl-2-pentene was hydrogenated to 2,3,4-trimethyl-pentane (bp $113.41^{\circ} \mathrm{C}, n_{D}^{20}=1.4038$ to 1.4040$)$.

An approximate analysis of the original diisobutylene (gas-free basis) was made by examination of the distillation curves. This mixture was found to contain.

\begin{tabular}{|c|c|}
\hline & $\begin{array}{l}\text { Percent } \\
\text { (by volume }\end{array}$ \\
\hline 2,4,4-Trimethyl-1-pentene $\ldots \ldots$ & 70.0 \\
\hline 2,4,4-Trimethyl-2-pentene - - & 18.7 \\
\hline 3,4,4-Trimethyl-2-pentene $\ldots \ldots$ & $\ldots \quad 4.6$ \\
\hline 2,3,4-Trimethyl-2-pentene $\ldots \ldots$ & 3. 7 \\
\hline 2,3,4-Trimethyl-1-pentene, & \\
\hline $\begin{array}{l}2,3,3 \text {-Trimethyl-1-pentere, and other } \\
\text { octene(s). }\end{array}$ & 1. 0 \\
\hline Other compounds & $\ldots \quad 2.0$ \\
\hline
\end{tabular}

29. Investigation of "Hot Acid Polymer"

The investigation of "hot acid polymer" (Shell Oil Co.) was undertaken to isolate and purify some of the major constituents. The general method of operation was the same as that used in the investigation of "diisobutylenes," but for this work more efficient, higher-capacity stills (numbers 12, 13, 14, and 16) were available.

A total of 1,041 liters of crude polymer was subjected to preliminary fractionation in five batches. Corresponding cuts from the several batches were combined. In this way, the polymer was divided into five portions. The data on these fractionations are given in table 9 .

Cut $A$, which contained butanol-2, was not further investigated. Likewise, the residue has not been studied. 
TABLE 9.-Division of "hot acid polymer" by preliminary fractionation

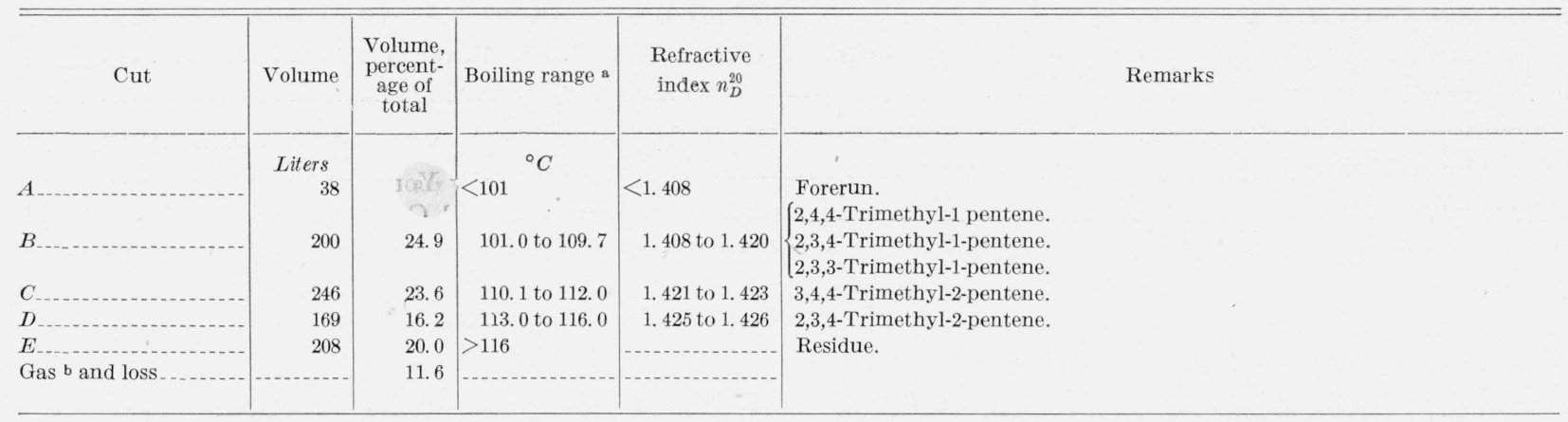

a Cottrell boiling-point measurements on first and last fractions.

b A preliminary distillation of 2 liters indicated over 10 percent of gas.

By refractionation of cut $B$, there was isolated the following materials:

Cut B-1: 103 liters, 2,4,4-trimethyl-1-pentene, bp 101.1 ${ }^{\circ}$ to $101.3^{\circ} \mathrm{C} / 755 \mathrm{~mm} \mathrm{Hg}, n_{D}^{20}=1.4084$ to 1.4086 .

Cut B-2: 9.5 liters, a mixture of close-boiling olefins, bp $107.0^{\circ}$ to $107.1^{\circ} \mathrm{C} / 756 \mathrm{~mm} \mathrm{Hg}, n_{D}^{20}=$ 1.4144 to 1.4146 .

Cut B-3: 8.0 liters, 2,3,3-trimethyl-1-pentene, bp $108.0^{\circ}$ to $108.1^{\circ} \mathrm{C} / 753 \mathrm{~mm} \mathrm{Hg}, n_{D}^{20}=1.4173$ to 1.4175 .

A considerable amount of material between $B-1$ and $B-2$ has not yet been investigated. This intermediate contains 2,4,4-trimethyl-2-pentene, associated with at least two other compounds whose boiling points are near $105^{\circ} \mathrm{C}$.

Cut $B-2$ was refractionated. The presence of several compounds is indicated by the distillation data. A sample of $B-2$ was hydrogenated. Analysis of the product showed the presence of about 30 percent of $2,2,3-$ and 70 percent of 2,3,4-trimethylpentanes.

Cut $B-3$ was refractionated for isolation of a sample suitable for physical constant measurements. A sample of this material was oxidized to methyl $t$-amyl ketone (bp $130.8^{\circ}$ to $131.2^{\circ} \mathrm{C}$, $n_{D}^{20}=1.4201$ ), whose 2,4-dinitrophenylhydrozone melted at $111^{\circ}$ to $112^{\circ} \mathrm{C}$. Hydrogenation of a sample yielded 2,3,3-trimethylpentane (bp $114.5^{\circ}$ C, $\left.n_{D}^{20}=1.4073\right)$.

Purification by refractionation of cut $C$ gave 100 liters of purified 3,4,4-trimethyl-2-pentene, bp $111.7^{\circ}$ to $111.9^{\circ} / 751 \mathrm{~mm} \mathrm{Hg}, n_{D}^{20}=1.4231$ to 1.4233. The best sample from this fraction was used to determine the physical constants. The presence of cis and trans isomers, which were only partially separated by the fractionation, causes the wide boiling range. It is thought that the sample reserved for physical-constant measurements contained more of the higher-boiling (trans?) isomer than of the lower-boiling compound. Oxidation of this compound by sodium dichromate produced pinacolone in 30 percent yield.

Redistillation of 120 liters of cut $D$ gave 45 liters of 2,3,4-trimethyl-2-pentene, bp $116.0^{\circ} \mathrm{C} / 754 \mathrm{~mm}$, $\mathrm{Hg}, n_{D}^{20}=1.4271$ to 1.4272 .

Acknowledgment is made to Alexandra de Glazoff, Anne Monmonier, Marie F. Whitesell, Millicent L. Yamin, and Messrs. Hugh C. Crafton, Jr., Samuel Goldhagen, Harry Kahn, Frank P. Lloyd, Louis N. Martin, and Edwin H. Rich for carrying out part of the laboratory work.

Thanks are due the following persons for advice on various problems: Cecil E. Boord, Ohio State University, George Calingaert, Ethyl Corporation Research Laboratories, Nathan L. Drake, University of Maryland, Merrill R. Fenske, Pennsylvania State College, Frederick D. Rossini, National Bureau of Standards, Harold A. Soroos, Ethyl Corporation Research Laboratories, and Frank C. Whitmore, Pennsylvania State College.

\section{References}

[1] Homer Adkins, Reactions of hydrogen, chapter III. (Univ. of Wisconsin Press, 1937).

[2] John G. Aston and George H. Messerly, J. Am. Chem. Soc. 58, 2354 (1936).

[3] Paul D. Bartlett and Abraham Schneider, J. Am. Chem. Soc. 6\%, 141 (1945).

[4] Donald B. Brooks, Robetta B. Cleaton, and Frank R. Carter, J. Research NBS 19, 319 (1937) RP1027.

[5] Donald B. Brooks, J. Research NBS 21, 847 (1938) RP1160. 
[6] Donald B. Brooks, Frank L. Howard, and Hugh C. Crafton, Jr., J. Research NBS 23, 637 (1939) RP1259.

[7] Donald B. Brooks, Frank L. Howard, and Hugh C. Crafton, Jr., J. Research NBS 24, 33 (1940) RP1271.

[8] Johannes H. Bruun, Ind. and Eng. Chem., Anal. Ed. 8, 224 (1936).

[9] George Calingaert, Harold Beatty, and Harold Soroos, Ethyl Corporation Research Laboratories, Detroit, Mich. Private communication.

[10] E. T. Cline, Ph. D. Thesis, Ohio State Univ. (1940).

[11] Robert A. Dinerstein, Thesis, Penn. State College (1940).

[12] Nathan L. Drake and Alexander Sadle, Univ. of Maryland, College Park, Md. Private communication.

[13] Gustav Egloff, Physical constants of hydrocarbons, volume I, (Reinhold Pub. Corporation, New York, N. Y., 1939).

[14] Charles R. Enyeart, Ph. D. Thesis, Penn. State College (1942).

[15] Al Faworsky, J. prakt. Chem. 88, 651 (1913).

[16] Merrill R. Fenske, Penn. State College. Private communication.

[17] A. Haller and Ed. Bauer, Compt. rend. 150, 582 (1910)

[18] J. W. Heyd, Ph.D. Thesis, Penn. State College (1937).

[19] Frank L. Howard, J. Research NBS 24, 677 (1940) RP1306.

[20] G. B. Kistiakowsky, John R. Ruhoff, Hilton A. Smith, and W. E. Vaughan, J. Am. Chem. Soc. 58, 137 (1936).

[21] F. D. Kuykendall, Ph. D. Thesis, Ohio State Univ. (1935).

[22] R. 3 Locquin and W. Sung, Compt. rend. 178, 1179 (1924).

[23] R. Locquin and W. Sung, Bul. Soc. chim. [4] 35, 753 (1924).

[24] B. J. Mair, BS J. Research 9, 457 (1932) RP482.
[25] George Moersch, Ph. D. Thesis, Penn. State College (1942).

[26] J. U. Nef, Ann 310, 316 (1899).

[27] Organic synti as, Collective volume I, page 448, (John Wiley Sons, Inc., New York, N. Y. 1932).

[28] Organic synthes Collective volume II, page 404, (John Wiley \& ns, Inc., New York, N. Y. 1943).

[29] Organic syntheses, ume XX, page 86, (John Wiley \& Sons, Inc., New k, N. Y. 1940).

[30] Iman Schurman and vecil E. Boord, J. Am. Chem. Soc. 55, 4930 (1933).

[31] This paper.

[32] C. O. Tongberg, J. D. Pickens, M. R. Fenske, and Frank C. Whitmore, J. Am. Chem. Soc. 54, 3706 (1932).

[33] Frank C. Whitmore and D. E. Badertscher, J. Am. Chem. Soc. 55, 1559 (1933).

[34] Frank C. Whitmore and James M. Church, J. Am. Chem. Soc. 54, 3710 (1932).

[35] Frank C. Whitmore and Newell C. Cook, J. Am. Cbem. Soc. 63, 3540 (1941).

[36] Frank C. Whitmore and George H. Fleming, J. Am. Chem. Soc. 55, 3803 (1933).

[37] Frank C. Whitmore, A. H. Homeyer, and W. R. Trent, U. S. Patent 2,004,066, June 4, 1935.

[38] Frank C. Whitmore and Kenneth C. Laughlin, J. Am. Chem. Soc. 55, 3732 (1933).

[39] Frank C. Whitmore, Kenneth C. Laughlin, John F. Matuszeski, and J. D. Surmatis, J. Am. Chem. Soc. 63, 756 (1941).

[40] Frank C. Whitmore and Albert R. Lux, J. Am. Chem. Soc. 54, 3451 (1932).

[41] Frank C. Whitmore, R. E. Marker, and Louis Plambeck, Jr., J. Am. Chem. Soc. 63, 1626 (1941).

[42] Wm. G. Young and John D. Roberts, J. Am. Chem. Soc. 66, 1444 (1944).

[43] J. A. C. Yule and C. P. Wilson, Jr., Ind. and Eng. Chem. 23, 1254 (1931).

Washington, July 30, 1946. 